Universidade de São Paulo

Faculdade de Medicina de Ribeirão Preto

Departamento de Farmacologia

\title{
EFEITOS CARDIOVASCULARES CAUSADOS PELA MICROINJEÇÃO DE ANGIOTENSINA II NO CÓRTEX PRÉ-LÍMBICO DE RATOS
}

\section{Bruna Muza Nogari}

RIBEIRÃO PRETO 


\author{
Universidade de São Paulo \\ Faculdade de Medicina de Ribeirão Preto \\ Programa de Pós-Graduação em Farmacologia
}

\title{
EFEITOS CARDIOVASCULARES CAUSADOS PELA MICROINJEÇÃO DE ANGIOTENSINA II NO CÓRTEX PRÉ-LÍMBICO DE RATOS
}

\section{Bruna Muza Nogari}

\begin{abstract}
Dissertação apresentada à Faculdade de Medicina de Ribeirão Preto da Universidade de São Paulo para obtenção do título de Mestre, pelo Programa de Pós-graduação em Ciências.
\end{abstract}

Área de concentração: Farmacologia

Orientador: Prof. Dr. Fernando Morgan de Aguiar Corrêa 
AUTORIZO A REPRODUÇÃO TOTAL OU PARCIAL DESTE TRABALHO, POR QUALQUER MEIO CONVENCIONAL OU ELETRÔNICO, PARA FINS DE ESTUDO

E PESQUISA, DESDE QUE CITADA A FONTE.

FICHA CATALOGRÁFICA

Preparada pela Biblioteca Central do Campus Administrativo de

Ribeirão Preto/USP

Nogari, Bruna Muza

Efeitos cardiovasculares causados pela microinjeção de angiotensina II no córtex pré-límbico de ratos. Ribeirão Preto, 2015.

79p. il. $30 \mathrm{~cm}$.

Dissertação de Mestrado apresentada à Faculdade de Medicina de Ribeirão Preto/USP.

Área de concentração: Farmacologia.

Orientador: Corrêa, Fernando Morgan de Aguiar

1. Angiotensina. 2. Pressão Arterial.

3. Freqüência Cardíaca. 4. Córtex Pré-Límbico. 


\section{EFEITOS CARDIOVASCULARES CAUSADOS PELA MICROINJEÇÃO DE ANGIOTENSINA II NO CÓRTEX PRÉ-LÍMBICO DE RATOS}

Bruna Muza Nogari

Dissertação apresentada à Faculdade de Medicina de Ribeirão Preto da Universidade de São Paulo para obtenção do título de Mestre, pelo Programa de Pós-graduação em Ciências. Área de concentração: Farmacologia

Aprovado em:

\section{Banca Examinadora}

Prof. Dr. Fernando Morgan de Aguiar Corrêa.

Instituição: FMRP-USP.

Assinatura:

Prof. Dr. Rubens Fazan Junior Instituição: FMRP-USP Assinatura:

Prof. Dra. Karen Barros Parron Fernandes

Instituição: FORP-USP Assinatura: 
Combati o bom combate, terminei a corrida, guardei a fé.

(2 Timóteo 4:7) 


\section{Dedico,}

A Deus, por seu imenso amor por mim, sua ajuda e não ter desistido e sonhado comigo esse sonho e me mostrado que tudo tem seu tempo sem me desamparar e colocado a cada passo pessoas especiais que me ajudaram nessa caminhada.

Aos meus pais, Maria Eunice Muza Nogari e Francisco Cesar Nogari Sobrinho pelo amor, paciência, dedicação, e apoio para ir atrás dos meus objetivos sempre incentivando os meus estudos não medindo esforços seja em palavras nas horas difíceis ou expressando carinho para que isso se tornasse realidade, não me deixando desistir. Uma forma mais especial a mamãe que compartilhou mais a fundo comigo cada momento e com amor, palavras sábias e orações sendo um porto seguro de um jeito inefável. Muito obrigado por tudo, amo vocês.

As tias tão amadas Ester de Góes Maciel, Joana Muza e Benedita Muza que são como mães para mim, sem vocês não teria conseguido, agradeço por vocês existirem, por confiarem, acreditarem e pelas palavras de força e amor quando sempre precisei, são importantíssimas pra mim. 


\section{AGRADECIMENTOS}

Ao Prof. Dr. Fernando Morgan de Aguiar Côrrea, por ter me aceitado como sua aluna. Agradeço por ter me dado a oportunidade de aprender em seu laboratório, de confiar esse trabalho a mim e ajudar em minhas dificuldades sempre com paciência. Admiro seu trabalho e conduta profissional. A você 'teacher', meu muito obrigada.

Aos membros da banca, por se disporem a participar, pela avaliação e contribuição com sugestões para o engrandecimento deste trabalho.

A Prof. Dra. Karen Fernandes Parron, que contribuiu e incentivou o meu início na área cientifica. A você minha admiração como pessoa, pesquisadora e professora.

A Idália I.B. Aguiar por me ensinar, auxiliar e supervisionar desde o início nas técnicas e cirurgias.

A Ivanilda A.C. pelo cuidado, atenção que tinha de um jeito especial, pela amizade e sem esquecer as caronas e brincadeiras.

Diva e Eliane pelo bom humor, cuidado com nossos animais e vidrarias.

A Simone S. Guilhaume, pela atenção, ajuda e pelas boas sugestões de alimentação.

Aos meus amigos e companheiros de laboratório: América Scopinho, Cristiane Busnardo, Eduardo Fortaleza, Fernando Alves, Milena Deolindo, Silvana Lopes Azevedo e cada um do seu jeito me proporcionou momentos agradáveis, ensinamentos e me ajudaram sempre que precisei, em especial a Aline Fassini pela parceria e orientação. 
Ao grande amigo, Alexandre Correa Cirelli pelas risadas, conversas, companheirismo, e todo ouvidos nos momentos de estresse.

Ao Edivaldo Paciência Vietta e sua família pelo carinho.

Ao insuportável e amável, Frederico Fábio Magosso por fazer parte quando possível.

A família Nemoto, pelas muitas hospedagens, amizade, risadas e pelo carinho.

A amiga linda e querida, Franciele de Sousa Balmant, pelo eterno apoio e sua positividade para que tudo desse certo.

Aos queridos, Daniel Assis e Clarice Luiza de Assis (In Memoriam) pela força, apoio e todo carinho que tiveram com uma desconhecida. Eternamente grata a vocês.

Ao Pr. Davis, Silmeire, Davi e Flavinha que me acolheram em sua casa.

Aos colegas de moradia, Felipe Freitas, Gustavo Henrique, Luís Henrique, Airton Junior pelas conversas, comidas e amizade.

A todos os meus familiares que sempre torceram pelo meu sucesso.

Aos meus amigos Londrinenses que sempre acreditaram, me apoiaram e torceram por mim.

A todos que direta ou indiretamente contribuíram para o desenvolvimento deste trabalho.

Ao CNPq e CAPES pelo auxílio financeiro durante a realização deste trabalho. 


\section{RESUMO}

NOGARI, B. M. Efeitos cardiovasculares causados pela microinjeção de angiotensina II no córtex pré-límbico de ratos. 2015. 79p. Dissertação (mestrado) Faculdade de Medicina de Ribeirão Preto, Universidade de São Paulo, Ribeirão Preto, 2015.

Estudos relatam alterações cardiovasculares após a estimulação química ou elétrica do córtex pré-límbico $(\mathrm{PL})$ em ratos. O sistema renina-angiotensina (SRA) central está envolvido na regulação do sistema cardiovascular, tendo como um dos principais componentes ativos desse sistema a angiotensina II (ANGII). Além disso, foi demonstrada a presença de um sistema SRA funcional no PL, com a presença de peptídeos e receptores angiotensinérgicos. Sendo assim, o objetivo do presente estudo foi investigar se a estimulação do PL com ANG II induz respostas cardiovasculares mediadas por ativação do sistema nervoso simpático ou por liberação de vasopressina. A microinjeção de ANGIl no $\mathrm{PL}$ de ratos não anestesiados causou resposta pressora e bradicardíaca de forma dose-dependente. O pré-tratamento sistêmico com o bloqueador ganglionar, pentolínio $(5 \mathrm{mg} / \mathrm{Kg})$, não alterou a resposta pressora, mas bloqueou a resposta bradicárdiaca causada pela microinjeção de ANGII no PL, sugerindo que o sistema nervoso simpático não medeia a resposta pressora. Além disso, o pré-tratamento sistêmico com antagonista dos receptores vasopressinérgicos do tipo $\mathrm{V} 1$, o dTyr $(\mathrm{CH} 2) 5(\mathrm{Me}) \mathrm{AVP}$ $(50 \mu \mathrm{g} / \mathrm{kg})$, bloqueou as respostas cardiovasculares causadas pela microinjeção de ANGII no $\mathrm{PL}$, demonstrando o envolvimento do mecanismo vasopressinérgico humoral na mediação destas respostas. Centralmente, o pré-tratamento do PL com o antagonista $A T_{1}$, candesartan, bloqueou a resposta cardiovascular induzida pela microinjeção de ANGII, assim como o pré-tratamento com CGP42112A, antagonista $A T_{2}$, foi capaz de atenuar as respostas cardiovasculares induzidas pela microinjeção de ANGII, sugerindo o envolvimento de ambos os receptores no desencadeamento dessas respostas cardiovasculares. Foi investigada a participação do sistema noradrenérgico no desencadeamento das respostas cardiovasculares à ANGII, através da administração local de um antagonista de receptores $\alpha_{1}$ - adrenérgicos, o WB4101; o qual foi efetivo em reduzir a resposta pressora sem alterar a resposta bradicardíaca à ANGII. Em conclusão, a administração de ANGll no PL de ratos não-anestesiados, através da estimulação de receptores AT1 e AT2, evoca respostas pressoras e bradicardíacas mediadas por liberação sistêmica de vasopressina, envolvendo também a participação do sistema noradrenérgico do PL.

Palavras chaves: Angiotensina, Pressão Arterial, Freqüência Cardíaca, Córtex PréLímbico. 


\begin{abstract}
NOGARI, B. M. Cardiovascular effects induced by angiotensin II microinjection in the prelimbic cortex of rats. 2015. 79p. Thesis (MSc) - School of Medicine of Ribeirão Preto, University of São Paulo, Ribeirão Preto, 2015.

Previous studies have reported cardiovascular responses after chemical or electrical stimulation of the prelimbic cortex (PL) in rats. The central renin-angiotensin system (RAS) is involved in the regulation of the cardiovascular system, being angiotensin II (ANG II) one of the major active components of this system. Furthermore, there are angiotensinergic receptors and peptides in the $\mathrm{PL}$, indicating the presence of a functional RAS in this brain area. Thus, the aim of this study was to investigate if the PL stimulation with ANG II induces cardiovascular responses mediated by activation of the sympathetic nervous system or through the release of vasopressin. ANG II microinjection into the PL of anesthetized rats caused pressor and bradycardiac responses, in a dose-dependent manner. Systemic pretreatment with the ganglionic blocker pentolinium $(5 \mathrm{mg} / \mathrm{kg}$ ) did not affect the pressor response, but blocked the bradycardiac response induced by ANG II, suggesting that the sympathetic nervous system does not mediate the pressor response. Furthermore, systemic pretreatment with the V1-vasopressinergic receptor antagonist, dTyr (CH2) 5 (Me) AVP (50 mg / $\mathrm{kg}$ ) blocked the cardiovascular responses caused by the microinjection of ANG II into the $\mathrm{PL}$, demonstrating the involvement of the humoral vasopressinergic mechanism in the mediation of these responses. PL pretreatment with the $\mathrm{AT}_{1}$ antagonist candesartan blocked the cardiovascular response induced by the microinjection of ANG II, while PL pretreatment with CGP42112A, an AT2 antagonist, attenuated the cardiovascular responses induced by microinjection of ANG II, suggesting the local involvement of both receptors in triggering these cardiovascular responses. We also investigated the participation of the local noradrenergic system in the triggering of cardiovascular responses to ANG II pretreating the PLwith the a1- adrenergic receptor antagonist WB4101. The pretreatment with WB4101 reduced the pressor response without changing the bradycardiac response. In summary, administration ANG II into the PL of non-anesthetized rats evoked pressor and bradycardiac responses mediated by local stimulation of AT1 and AT2 receptors, with concomitant involvement PL noradrenergic mechanisms, and systemic release of vasopressin.
\end{abstract}

Keywords: angiotensin, arterial pressure, heart rate, prelimbic cortex 


\section{SUMÁRIO}

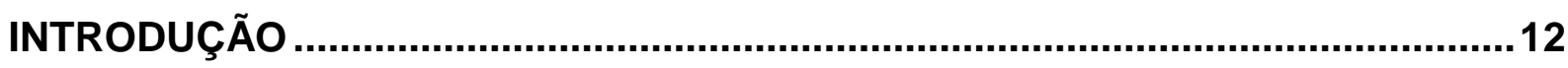

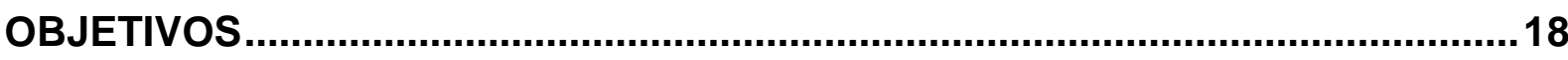

MATERIAIS E MÉTODOS ................................................................................ 20

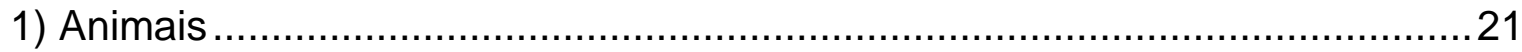

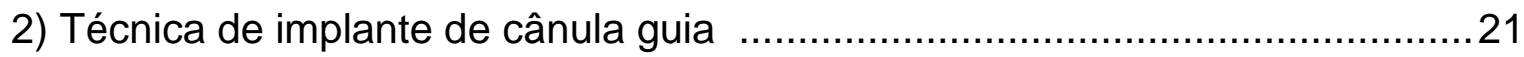

3) Canulação da artéria e veia femoral ................................................. 22

4) Registro de pressão arterial e frequência cardíaca ..................................22

5) Técnica de microinjeção de drogas .................................................. 23

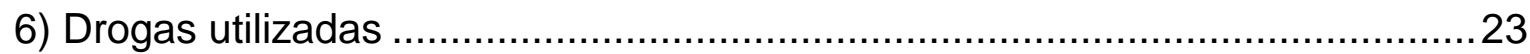

7) Determinação anatômica dos sítios de injeção de drogas .............................25

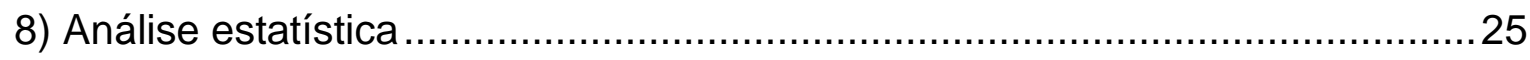

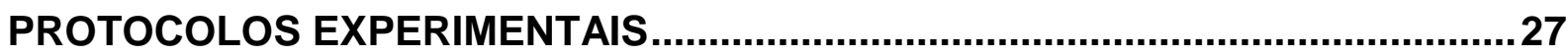

1. Efeito da administração de diferentes doses de ANGll sobre a PA e FC de ratos não anestesiados (curva dose-resposta) ............................................ 28

2. Efeito da administração periférica de bloqueador ganglionar sobre as respostas cardiovasculares à microinjeção de ANGII no PL de ratos ..................28

3. Efeito da administração periférica de antagonista de receptores vasopressinérgicos sobre as respostas cardiovasculares à microinjeção de ANGII no PL de ratos

4. Efeito da microinjeção de antagonista do receptor $A T_{1}$ no $P L$ sobre as respostas cardiovasculares à microinjeção local de ANGIl.

5. Efeito da microinjeção de antagonista do receptor $\mathrm{AT}_{2}$ no $\mathrm{PL}$ sobre as respostas cardiovasculares à microinjeção local de ANGll..............................29

6. Efeito da microinjeção de antagonista do receptor a1-adrenérgico no PL sobre as respostas cardiovasculares à microinjeção local de ANGll 29 
1. Efeito da administração de diferentes doses de ANGll sobre a PA e FC de ratos não anestesiados (curva dose-resposta)

2. Efeito da microinjeção de NA em áreas fora do PL sobre a pressão arterial e frequência cardíaca de ratos

3. Efeito da administração periférica de veículo sobre as respostas cardiovasculares à microinjeção de ANGII no PL de ratos 38

4. Efeito da administração periférica de bloqueador ganglionar sobre as respostas cardiovasculares à microinjeção de ANGII no PL de ratos

5. Efeito da administração periférica de antagonista de receptores vasopressinérgicos sobre as respostas cardiovasculares à microinjeção de ANGll no $\mathrm{PL}$ de ratos

6. Efeito da microinjeção de LCA no PL sobre as respostas cardiovasculares à microinjeção local de ANGlI

7. Efeito da microinjeção de antagonista do receptor $A T_{1}$ no $P L$ sobre as respostas cardiovasculares à microinjeção local de ANGIl.

8. Efeito da microinjeção de antagonista do receptor AT2 CGP42112A no PL sobre as respostas cardiovasculares à microinjeção local de ANGII

9. Efeito da microinjeção de antagonista do receptor AT2 PD123319 no PL sobre as respostas cardiovasculares à microinjeção local de ANGII

10. Efeito da microinjeção de antagonista do receptor a1- adrenérgico no PL sobre as respostas cardiovasculares à microinjeção local de ANGll 
INTRODUÇÃO 
O sistema cardiovascular é responsável pelo fluxo sanguíneo adequado a diferentes órgãos e tecidos do corpo. Importantes áreas do sistema nervoso central (SNC) estão envolvidas no controle do sistema cardiovascular, tais como regiões bulbares e supra-bulbares. Entre os centros bulbares destaca-se o núcleo do trato solitário (NTS) que recebe fibras aferentes de locais responsáveis pelos reflexos cardíacos, tais como seio carotídeo e o nervo depressor aórtico (NDA), modulando o barorreflexo, quimiorreflexo e o reflexo cardiopulmonar, os quais permitem ajustes instantâneos na pressão arterial em respostas a alterações posturais, respiratórias e de volume sanguíneo (GOLDSTEIN, 1991; GUYENET, 2006; MIURA; REIS, 1969; TAYLOR; JORDAN; COOTE, 1999). Assim como o NTS, os núcleos rostroventrolateral (RVLM) e caudoventrolateral (CVLM) estão envolvidos na regulação e manutenção da pressão arterial (PA) e frequência cardíaca (FC) (CHALMERS; PILOWSKY, 1991; GOLDSTEIN, 1991). Os neurônios do RVLM determinam a frequência de descarga dos neurônios pré-ganglionares simpáticos envolvidos na manutenção do tônus vascular (GUYENET; DARNALL; RILEY, 1990; VERBERNE; OWENS, 1998) e medeiam o componente simpático dos reflexos cardiovasculares (GUYENET et al., 1990).

Devido a conexões entre as estruturas prosencefálicas e estruturas do tronco encefálico, áreas supra-bulbares podem influenciar os neurônios bulbares (DAMPNEY et al., 1987; HILTON, 1966; LOEWY, 1991; LOEWY; MCKELLAR, 1980; VERBERNE, 1995;1996; VERBERNE; GUYENET, 1992; VERBERNE; OWENS, 1998). Dentre estas estruturas prosencefálicas se destacam o hipotálamo, amígdala, área septal e em particular, regiões específicas do córtex cerebral (DAMPNEY, 1994; FORTALEZA; SCOPINHO; CORRÊA, 2011; LOEWY, 1991; LOEWY; MCKELLAR, 1980; RESSTEL; CORRÊA, 2005; SCOPINHO et al., 2006). 
O córtex pré-frontal (CPF) é dividido em córtex pré-frontal medial (CPFM), lateral (CPFL) e córtex pré-frontal orbital (NEAFSEY, 1990). O CPFM é subdividido em porção dorsal e ventral (CPFMv), sendo a porção ventral compreendida pelo córtex pré-límbico (PL), córtex infralímbico (IL) e córtex dorsopeduncular (DP) (PAXINOS; WATSON, 1997).

Estudos relatam alterações cardiovasculares após a estimulação do CPFM (FISK; WYSS, 1997;2000; OWENS; SARTOR; VERBERNE, 1999; OWENS; VERBERNE, 2000; VERBERNE, 1996). Em ratos não-anestesiados, a estimulação elétrica causa resposta pressora, enquanto em ratos anestesiados a mesma estimulação causa resposta depressora (BURNS; WYSS, 1985; TAVARES; ANTUNES-RODRIGUES; DE AGUIAR CORRÊA, 2004). Foi descrito que a estimulação elétrica ativa tanto corpos celulares quanto fibras de passagem (GOODCHILD; DAMPNEY; BANDLER, 1982), porém as respostas cardiovasculares observadas após a estimulação elétrica do CPFM não se devem à estimulação de fibras de passagem, pois a estimulação química da mesma área é capaz de evocar respostas semelhantes. Em ratos não-anestesiados, a estimulação química do CPFMv, com noradrenalina (NA), causa resposta pressora e bradicardíaca, mediada por liberação de vasopressina (FERNANDES et al., 2003); enquanto resposta pressora e taquicardíaca foi observada após a estimulação local com glutamato, devido à ativação do sistema nervoso simpático (RESSTEL; CORREA, 2006).

Além disso, foi relatado que o CPFMv está envolvido na modulação da atividade do barorreflexo, atuando tanto no componente simpático como no parassimpático (FERREIRA-JUNIOR et al., 2012; RESSTEL; FERNANDES; CORRÊA, 2004). Apesar de vários trabalhos da literatura evidenciarem o papel do 
CPFMv na modulação do sistema cardiovascular, as neurotransmissões envolvidas nessa modulação não estão totalmente elucidadas.

O sistema renina-angiotensina (SRA) está envolvido na regulação do sistema cardiovascular, controle hidroeletrolítico, secreção hormonal, ansiedade, comportamento sexual, atividade pró-inflamatória, entre outras (BENICKY et al., 2011; BREIGEIRON et al., 2002; CHIARAVIGLIO, 1976; LÓPEZ et al., 2012; SAAVEDRA, 1992). Um dos componentes ativos do SRA, a angiotensina II (ANGII), é um octapeptídeo (Asp-Arg-Val-Tyr-Ile-His-Pro-Phe) produzido pela ação da enzima conversora de angiotensina (ECA) sobre a angiotensina I (ANG I), um decapeptídeo (Asp-Arg-Val-Tyr-lle-His-Pro-Phe-His-Leu) clivado a partir do angiotensinogênio pela enzima renina (PAGE et al., 1943; PEACH, 1977). Perifericamente, a ANG II apresenta efeito vasoconstritor na musculatura lisa vascular, promove liberação de aldosterona, e retenção renal de sódio e água, visando manter a homeostase cardiovascular (BATIN et al., 1991; HALL, 1991). Há cinquenta anos tornou-se claro que, além de suas ações periféricas, a ANGIl seria capaz de agir também no SNC (BICKERTON; BUCKLEY, 1961). Foi demonstrada a presença de angiotensinogênio (DESCHEPPER; BOUHNIK; GANONG, 1986; STORNETTA et al., 1988; THOMAS; SERNIA, 1988) e da enzima renina em células da glia e em neurônios (HERMANN et al., 1987), além de expressão da ECA no plexo coróide, órgão subfornical, órgão vasculoso da lamina terminal, na área postrema, e em grandes quantidades no hipotálamo, ao longo dos gânglios basais e no bulbo (CHAI; MCKINLEY; MENDELSOHN, 1987), sugerindo que a síntese de ANGII também ocorra no SNC.

Vários trabalhos na literatura demonstraram a presença desse peptídeo em regiões hipotalâmicas, tais como os núcleos supraóptico (SON) e paraventricular (PVN), órgão subfornical (OSF), medula oblongata e o córtex cerebral (HEALY; 
PRINTZ, 1984; PRINTZ et al., 1982; SAAVEDRA et al., 1986). Existem três subtipos de receptores angiotensinérgicos: AT1, AT2 e AT4 (BUMPUS et al., 1991; CHIU et al., 1989; TIMMERMANS et al., 1992), distribuídos em regiões cerebrais relacionadas com a regulação cardiovascular, tais como o NTS, hipotálamo, amígdala, órgão vasculoso da lâmina terminal, orgão subfornical e o córtex, sobretudo o CPFM (HÄUSER; JÖHREN; SAAVEDRA, 1998; LENKEl et al., 1997; LIND; SWANSON; GANTEN, 1985; MENDELSOHN et al., 1983; MENDELSOHN et al., 1984; TSUTSUMI; SAAVEDRA, 1991; WRIGHT; HARDING, 1994), sugerindo um SRA funcional no CPFM. Particularmente, o receptor AT 1 está envolvido na liberação hormonal e controle homeostático, além de mediar respostas cardiovasculares (FERGUSON; WASHBURN; LATCHFORD, 2001; MATHAI; EVERED; MCKINLEY, 1997; NUNES; BRAGA, 2011; OSBORN et al., 2012; Ql et al., 2013; SASAKI; DAMPNEY, 1990).

Aparentemente, os efeitos cardiovasculares do SRA são mediados tanto pelo sistema nervoso simpático como pela liberação de vasopressina. Haack e Möhring (1978) demonstraram uma relação entre o efeito pressor e concentração sanguínea de vasopressina após a estimulação intracerebroventricular (i.c.v.) com ANG II, sendo o efeito pressor atenuado quando a vasopressina era inibida por anticorpos anti-vasopressina. Foi observado também o aumento de noradrenalina no PVN e SON após essa estimulação i.c.v. com ANG II (QADRI et al., 1993; STADLER et al., 1992). O antagonismo $\alpha_{1}$-seletivo bilateral do SON foi capaz de diminuir a liberação de vasopressina após estimulo i.c.v. com ANG II, assim como o bloqueio com losartan (antagonista de receptores $A T_{1}$ ), porém, o bloqueio bilateral do SON com losartan não foi capaz de inibir a liberação de vasopressina induzida pela estimulação local com noradrenalina, sugerindo que tanto receptores 
noradrenérgicos quanto receptores $A T_{1}$ estão envolvidos na liberação de vasopressina induzida por estímulo i.c.v. com ANGII. Além disso, a estimulação do SON com ANG II também é capaz de induzir a liberação periférica de vasopressina (QADRI et al., 1993). Em contrapartida, a administração de losartan no RVLM atenua o efeito pressor e simpato-excitatório observados após a estimulação com ANG II, evidenciando a modulação do SRA sobre a atividade do sistema nervoso simpático (AVERILL et al., 1994).

Baseado nos dados descritos acima, que revelam que o córtex PL está envolvido na modulação de respostas cardiovasculares; que o CPFMv apresenta receptores e peptídeos angiotensinérgicos, e que o SRA central modula o sistema cardiovascular, a hipótese do presente estudo foi que a estimulação do PL com ANG Il induz respostas cardiovasculares mediadas por ativação do sistema nervoso simpático e por liberação de vasopressina. 
OBJETIVOS 
Os objetivos do presente estudo foram:

1) Estudar os efeitos da microinjeção de doses crescentes de ANGIl no PL sobre o sistema cardiovascular de ratos (curva dose-resposta);

2) Determinar os mecanismos periféricos envolvidos na efetuação da resposta cardiovascular à microinjeção de ANGIl no PL.

3) Avaliar a participação dos receptores angiotensinérgicos no PL sobre a resposta cardiovascular induzida pela microinjeção local de ANGII;

4) Investigar a participação no sistema noradrenérgico local sobre a resposta cardiovascular induzida pela microinjeção de ANGll no PL. 
MATERIAIS E MÉTODOS 


\section{1) Animais.}

Os experimentos foram realizados em ratos machos Wistar com peso variando entre 240-290 g. Os animais foram fornecidos pelo biotério central da USP de Ribeirão Preto sendo mantidos em caixas individuais, com alimentação de ração e água. Os animais foram submetidos à alternância de luz (12 h claro /12 h escuro). O protocolo para uso de animais em experimentação seguiu as normas da Comissão de Ética em Experimentação Animal (CETAE) e está de acordo com os princípios éticos na experimentação animal adotado pelo Colégio Brasileiro de Experimentação Animal (COBEA), nº 074/2012.

\section{2) Técnica de implante de cânula-guia no PL.}

O anestésico utilizado para este procedimento cirúrgico foi ketamina-xilazina na dose de $1 \mathrm{~mL} / \mathrm{kg}$ (solução de $5 \mathrm{ml}$ de ketamina à $10 \%$ e $1,6 \mathrm{ml}$ de xilazina à $2 \%$ ) via intraperitonial. A cabeça do animal foi imobilizada em um estereotáxico (Stoelting, USA) e após tricotomia, foi feita assepsia do local com álcool a 70\%. A seguir, foi injetado $0,3 \mathrm{~mL}$ de lidocaína com vasoconstritor subcutaneamente para anestesia local do escalpo. A calota craniana foi exposta pela incisão na pele de aproximadamente $1,5 \mathrm{~cm}$, afastando-se todo o periósteo. A assepsia local foi feita com salina e água oxigenada a 10\%. As coordenadas utilizadas para o PL foram determinadas a partir do Atlas do cérebro de rato (PAXINOS; WATSON, 1997)

Ântero-posterior: + 3,3 mm em relação ao bregma

Lateral: + 1,9 mm em relação à sutura sagital

Vertical: - 2,4 mm em relação à estrutura óssea da calota craniana Inclinação lateral: $2^{\circ}$

Incisivo: $+3,2 \mathrm{~mm}$ 
Com o auxílio de broca odontológica, foi feita a trepanação do crânio e as cânulasguia foram introduzidas no PL. As cânulas são constituídas de segmentos de agulha hipodérmica com $11 \mathrm{~mm}$ de comprimento e 0,55 mm de diâmetro externo, 24G. Elas foram fixadas ao crânio com resina acrílica autopolimerizável e um pequeno parafuso sendo fixado na calota craniana. Mandris com 0,2 $\mathrm{mm}$ de diâmetro externo e $11 \mathrm{~mm}$ de comprimento foram introduzidos nas cânulas, com o objetivo de se evitar sua obstrução durante o período de recuperação pós-cirurgia. Ao final da cirurgia os animais receberão 0,3 mL de Pentabiótico veterinário (White, Brasil) por via intramuscular e 2,5 mg/Kg do analgésico e antiinflamatório flunixina meglumina (Banamine, Schering-Plough, Brasil) por via subcutânea.

\section{3) Canulação da artéria e veia femoral.}

Após 48 h da cirurgia para implante da cânula-guia no crânio, os animais foram novamente anestesiados com ketamina-xilazina e uma cânula de polietileno foi implantada na artéria femoral, sendo introduzida até a aorta abdominal inferior. A cânula é constituída por segmento de polietileno PE-10 $(4-5 \mathrm{~cm})$ fundido a segmento de polietileno PE-50 (14-15 cm), sendo preenchida com salina ( $\mathrm{NaCl}$ a $0,9 \%)$ contendo anticoagulante $(5 \mathrm{U} / \mathrm{mL}$ de heparina) e obstruída com um pino de metal. Quando a administração endovenosa de drogas foi necessária, um cateter similar foi introduzido na veia femoral. O animal foi mantido em caixa individual por um tempo de recuperação de 24 horas para posterior registro da PA e FC.

\section{4) Registro da pressão arterial e frequência cardíaca.}

A cânula implantada na artéria femoral foi conectada a um transdutor de pressão arterial (Hewlett Packard, USA) por meio de um segmento de polietileno PE- 
50. A PA e FC foram registradas por meio de um pré-amplificador de um polígrafo HP7754-A (Hewlett Packard, USA) conectado a um sistema de aquisição de dados computadorizado (MP-100, Biopac, USA). A cânula implantada na artéria femoral foi conectada ao transdutor de pressão para registro contínuo da pressão arterial e a frequência cardíaca, para posterior análise dos dados.

\section{5) Técnica para microinjeção de drogas no PL.}

As drogas foram dissolvidas em líquido cefalorraquidiano artificial (LCA) (NaCl 100mM; Na3PO4 2mM; KCL 2,5mM; MgCl2 1,0mM; NaHCO3 27mM; CaCl2 2,5mM; ph= 7,4), e administradas diretamente no PL. Quando necessário, após a dissolução o PH foi ajustado para 7,4. As microinjeções foram feitas utilizando-se uma seringa de $2 \mu \mathrm{L}$ (Hamilton, USA) conectada a um tubo de polietileno (PE-10) e a uma agulha injetora ( $185 \mu$ de diâmetro externo, 33 Gauge), $1 \mathrm{~mm}$ mais longa do que a cânulaguia fixada ao crânio, previamente preenchidos com água Milliq. A microinjeção de droga no PL foi feita no momento que a pressão arterial do animal encontrar-se estável. A seringa foi manipulada manualmente e somente 1 minuto após a microinjeção a agulha injetora é retirada.

\section{6) Drogas utilizadas.}

- Angiotensina II (SIGMA, USA). Para a realização da curva dose resposta, as doses utilizadas serão 0,1; 0,3; 0,4; 0,5 e 1nmol (COLOMBARI; CORREA, 1995);

- Pentolínio (Sigma, USA), bloqueador ganglionar. A dose de (5mg/Kg i.v.) foi determinada em experimentos realizados em nosso laboratório, a partir de trabalhos descritos na literatura (MATSUMURA et al., 2000; MORIGUCHI et al., 1998); 
- dTyr(CH2)5(Me)AVP (Península, USA), antagonista de receptores

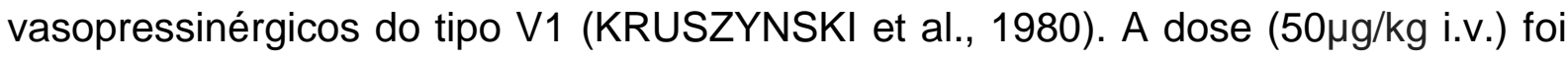
escolhida tendo-se como referência experimentos descritos na literatura (CORREA et al., 1985; FERNANDES et al., 2003; TAVARES; DE AGUIAR CORREA, 2003);

- Candesartan cilexitil (Sigma, USA), antagonista de receptores AT1. As doses utilizadas foram 0,1 e 0,03nmol/100nL;

- CGP42112A (Tocris, USA) antagonista de receptor AT2. As doses utilizadas foram 10 e $1 \mathrm{nmol} / 100 \mathrm{~nL}$;

- PD 123319 (Sigma, USA) antagonista de receptor AT2. A dose utilizada foi 0,1nmol/100nL (BERTRAM; COOTE, 2001);

- WB 4101 (RBI, USA) antagonista de receptores $\alpha_{1}$ - adrenérgicos. A dose utilizada $(10 \mathrm{nmol} / 100 \mathrm{~nL})$ foi escolhida tendo-se como referência experimentos descritos na literatura (FERNANDES et al., 2003);

- Líquido cefalorraquidiano artificial (LCA), composição: NaCl 100 mM; Na3PO4 2 mM; KCl 2,5 mM; MgCl2 1 mM; NaHCO3 27 mM; CaCl2 2,5 mM; $\mathrm{pH}=7,4)$;

- Salina ( $\mathrm{NaCl} 0,9 \%)$;

- Uretana (Sigma, USA), anestésico que será utilizado para a perfusão dos animais;

-Cloridrato de ketamina (Dopalen) e Xilazina (Dopaser), anestésico utilizado para os procedimentos cirúrgicos.

- Pentabiótico veterinário (Fontoura-Wyeth, Brasil), antibiótico que será administrado como profilático. 


\section{7) Determinação anatômica do sítio de injeção.}

Ao final de cada experimento, os animais foram anestesiados com uretana $(1,2 \mathrm{~g} / \mathrm{kg}$ i.p. .). O corante azul de Evans a $1 \%$ foi injetado no local da microinjeção das drogas, para determinação do sítio de injeção. Em seguida, os ratos foram submetidos à perfusão cerebral. Para isso, abre-se a caixa torácica para exposição do coração, e em seguida a aorta descendente é bloqueada com uma pinça hemostática. Uma agulha para perfusão é introduzida no ventrículo esquerdo, e uma incisão é feita na aurícula direita para o escoamento do sangue e do perfusado. A perfusão foi realizada inicialmente com $20 \mathrm{~mL}$ de solução fisiológica de $\mathrm{NaCl}$ 0,9\%, seguida por $20 \mathrm{~mL}$ de solução tamponada de formalina a $10 \%$. Posteriormente, os cérebros foram retirados da caixa craniana e pós-fixados em solução de perfusão. Os cérebros foram seccionados com o auxílio de um criostato. Foram feitas várias secções da área do PL, coradas com cresil violeta a 0,5\% e analisadas utilizando-se o atlas (PAXINOS; WATSON, 1997) como referência.

\section{8) Análise estatística.}

Os dados são expressos como média \pm erro padrão da média (EPM). A análise estatística dos dados foi realizada através do programa PRISM 3.0 (GraphPad, USA). Sendo utilizados os seguintes testes:

1) Regressão não-linear sigmoidal para construção da curva dose resposta;

2) Teste t de Student pareados, utilizado para comparar os valores de PAM e FC antes e após os tratamentos, assumindo-se $p<0,05$.

3) Análise de variância (Two-way ANOVA) de dois fatores (tratamento e tempo) para comparar os efeitos do tratamento sobre as repostas cardiovasculares à microinjeção de ANGIl no PL antes e após os pré- 
tratamentos. Os pontos mostrados durante três minutos antes da microinjeção de ANGII foram usados como valores de referência controle. Alterações na PAM e FC foram analisadas usando ANOVA de dois fatores com o tratamento como principal fator independente e o tempo como medida repetida. Quando a interação entre os fatores foi observada, os grupos foram comparados ponto a ponto usando o pós-teste de Bonferroni, assumindo-se $p<0,05$. 


\section{PROTOCOLOS EXPERIMENTAIS}


Para a realização dos experimentos, os animais foram levados em suas respectivas caixas à sala de experimentação. Cada animal foi conectado ao sistema de registro da pressão arterial, em sua respectiva caixa, para registro da PA e FC. Em todos os protocolos, as microinjeções de drogas foram feitas após a estabilização da pressão arterial e da frequência cardíaca dos animais.

1) Efeito da administração de diferentes doses de ANGll sobre a PA e FC de ratos não anestesiados (curva dose-resposta)

Este experimento teve por objetivo verificar as alterações cardiovasculares causadas pela microinjeção de doses crescentes de ANGII $(0,1 ; 0,3 ; 0,4 ; 0,5$ e 1 nmol/100nL) ou veículo (LCA) no PL. A dose de 0,4nmol/100nL próxima à ED50 foi utilizada nos protocolos subseqüentes.

2) Efeito da administração periférica de bloqueador ganglionar sobre as respostas cardiovasculares à microinjeção de ANGII no PL de ratos

Este experimento teve por objetivo verificar se a resposta cardiovascular a microinjeção de ANGII no PL é mediada pela ativação do sistema nervoso autônomo. O bloqueador ganglionar pentolínio $(5 \mathrm{mg} / \mathrm{kg})$ foi injetado endovenosamente dez minutos antes da microinjeção de ANGII no PL.

3) Efeito da administração periférica de antagonista de receptores vasopressinérgicos sobre as respostas cardiovasculares à microinjeção de ANGII no PL de ratos

Este experimento teve por objetivo verificar se a resposta cardiovascular a microinjeção de ANGll no PL é mediada pela liberação periférica de vasopressina. O 
antagonista de receptores V1 de vasopressina, dTyr(CH2)5(Me)AVP $(50 \mu \mathrm{g} / \mathrm{kg})$ ou foi injetado endovenosamente quinze minutos antes da microinjeção de ANGll no PL.

4) Efeito da microinjeção de antagonista do receptor $\mathrm{AT}_{1}$ no $\mathrm{PL}$ sobre as respostas cardiovasculares à microinjeção local de ANGII

O objetivo deste experimento foi averiguar se o receptor $\mathrm{AT}_{1}$ está envolvido na resposta cardiovascular desencadeada pela microinjeção de ANGII no PL. Para isso, os animais foram pré-tratados com veículo (LCA) ou doses crescentes de antagonista de receptores $A T_{1}$, candesartan no PL $(0,03 ; 0,1 \mathrm{nmol} / 100 \mathrm{~nL})$ dez minutos antes da microinjeção de ANGIl.

5) Efeito da microinjeção de antagonista do receptor $\mathrm{AT}_{2}$ no $\mathrm{PL}$ sobre as respostas cardiovasculares à microinjeção local de ANGII

O objetivo deste experimento foi averiguar se o receptor $\mathrm{AT}_{2}$ está envolvido na resposta cardiovascular desencadeada pela microinjeção de ANGll no PL. Para isso, os animais foram pré-tratados com veículo (LCA), antagonista de receptores AT2, PD123319 $(0,1 \mathrm{nmol} / 100 \mathrm{~nL})$ ou CGP42112A $(1 ; 10 \mathrm{nmol} / 100 \mathrm{~nL})$ no PL dez minutos antes da microinjeção de ANGII.

6) Efeito da microinjeção de antagonista do receptor $\alpha_{1}$ - adrenérgico no PL sobre as respostas cardiovasculares à microinjeção local de ANGII

O objetivo deste experimento foi averiguar se o receptor $\alpha_{1}$ - adrenérgico está envolvido na resposta cardiovascular desencadeada pela microinjeção de ANGII no PL. Para isso, os animais foram pré-tratados com veículo (LAC) ou antagonista de receptor $\alpha_{1}$ - adrenérgico WB 4101 (10nmol/100nL) no PL dez minutos antes da microinjeção de ANGII. 
RESULTADOS 


\section{1) Efeito da administração de diferentes doses de ANGll sobre a PA e FC de ratos não anestesiados (curva dose-resposta)}

A microinjeção de líquido cefalorraquidiano artificial (LCA) 100nL no PL não causou alterações significativas na PAM (ANTES: $105.2 \pm 2.20 \mathrm{mmHg}$; APÓS: 102.9 $\pm 2.99 \mathrm{mmHg}, \mathrm{t}=2.04$, teste $\mathrm{t}$ de student, $\mathrm{p}>0,05$ ) e FC (ANTES: $403.1 \pm 20.27$ bpm; APÓS: $408.2 \pm 20.14 \mathrm{bpm}, \mathrm{t}=2.13, \mathrm{p}>0.05, \mathrm{n}=5$ ).

A microinjeção de doses crescentes de ANGll $(0,1,0,3,0,4,0,5$ e 1 nmol/100nL) no $\mathrm{PL}$ de ratos normotensos causou respostas pressora e bradicardíaca de maneira dose-dependente (Figura 1 e Tabela 1). A análise de regressão não-linear do tipo sigmoidal indicou uma correlação significante entre a dose e a resposta pressora $\left(r^{2}=0,81\right)$ ou bradicárdica $\left(r^{2}=0,30\right)$. A dose de ANGll de 0,4nmol/100nL, foi utilizada nos experimentos subsequentes.

A análise de two-way ANOVA indicou um efeito significante da ANGII $(0,4 \mathrm{nmol} / 100 \mathrm{~nL})$ sobre as respostas pressora e bradicárdica (PAM: $\mathrm{F}_{1,120=258,0 ;} \mathrm{P}<$

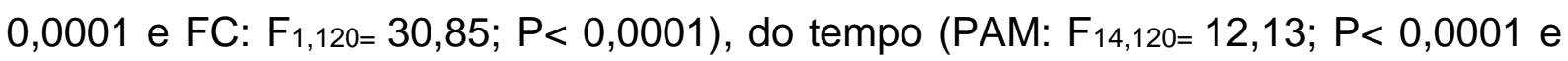
FC: $F_{14,120}=3,91 ; P<0,0001$ ), e interação entre tratamento e tempo (PAM: $F_{14,120=}$ 12,96; $\mathrm{P}<0,0001$ e $\left.F C: F_{14,120}=4,37 ; P<0,0001\right)$ quando comparado ao grupo que recebeu LCA (Figura 2).

O registro representativo de pressão arterial média, pressão arterial pulsátil e da frequência cardíaca de um animal representativo do grupo, que recebeu a microinjeção de ANGII (0,4nmol/100nL) está representado na figura 3. A figura 4 mostra a fotomicrografia de um corte de cérebro de rato mostrando o sítio de microinjeção de ANGll no PL. 
TABELA 1 - Variações máximas na pressão arterial média ( $\triangle P A M)$ e frequência cardíaca $(\triangle \mathrm{FC})$, em resposta a microinjeção de diferentes concentrações ANGIl no PL de ratos não anestesiados.

\begin{tabular}{|c|c|c|c|}
\hline $\begin{array}{c}\text { ANGII } \\
(\mathrm{nmol} / 100 \mathrm{~nL})\end{array}$ & $\begin{array}{c}\Delta \mathrm{PAM} \pm \mathrm{EPM} \\
(\mathrm{mmHg})\end{array}$ & $\begin{array}{c}\Delta \mathrm{FC} \pm \mathrm{EPM} \\
(\mathrm{bpm})\end{array}$ & $\begin{array}{c}\mathrm{N} \\
(\text { amostra })\end{array}$ \\
\hline $\mathrm{LCA}$ & $-1.801 \pm 0.66$ & $0.3021 \pm 2.28$ & $\mathrm{~N}=5$ \\
\hline 0,1 & $1.501 \pm 0.68$ & $-8.874 \pm 4.35$ & $\mathrm{~N}=5$ \\
\hline 0,3 & $13.79 \pm 2.54$ & $-25.67 \pm 8.38$ & $\mathrm{~N}=6$ \\
\hline 0,4 & $21.30 \pm 3.21$ & $-30.78 \pm 4.07$ & $\mathrm{~N}=5$ \\
\hline 0,5 & $23.28 \pm 4.84$ & $-50.33 \pm 6.83$ & $\mathrm{~N}=4$ \\
\hline 1 & $36.34 \pm 4.09$ & $-48.44 \pm 3.10$ & $\mathrm{~N}=5$ \\
\hline
\end{tabular}



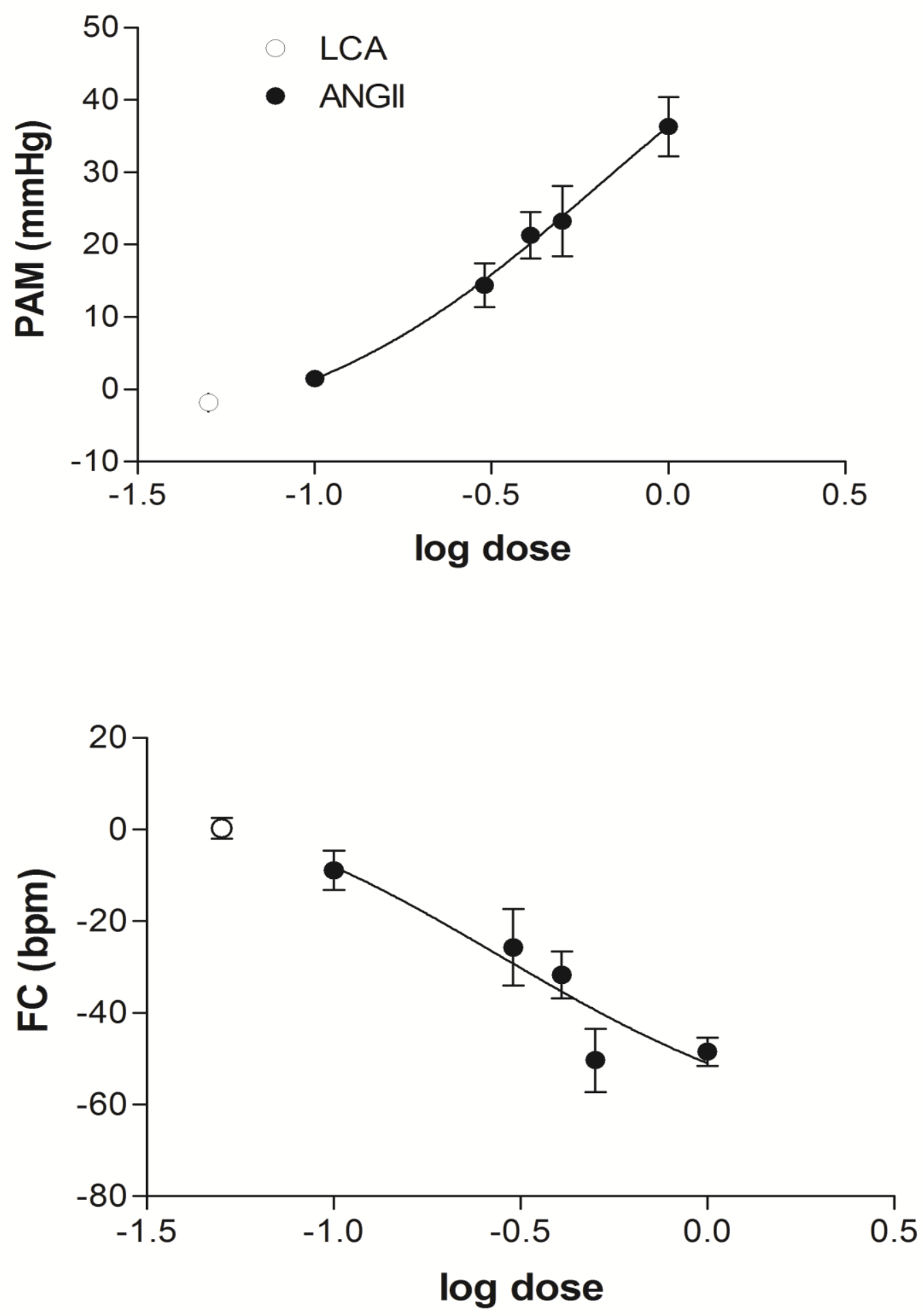

FIGURA 1 - Efeito da microinjeção de diferentes doses de ANGIl (círculos pretos, $\mathrm{n}=30$ ) ou líquido cefalorraquidiano artificial (LCA) (círculo branco, $n=5$ ) no PL de ratos não anestesiados, sobre a pressão arterial média $(\triangle P A M)$ e a frequência cardíaca $(\Delta \mathrm{FC})$. As doses injetadas foram: $0,1,0,3,0,4,0,5$ e $1 \mathrm{nmol} / 100 \mathrm{~nL}$. As curvas foram geradas por análise de regressão não linear. Os círculos representam as médias e as barras o EPM. 

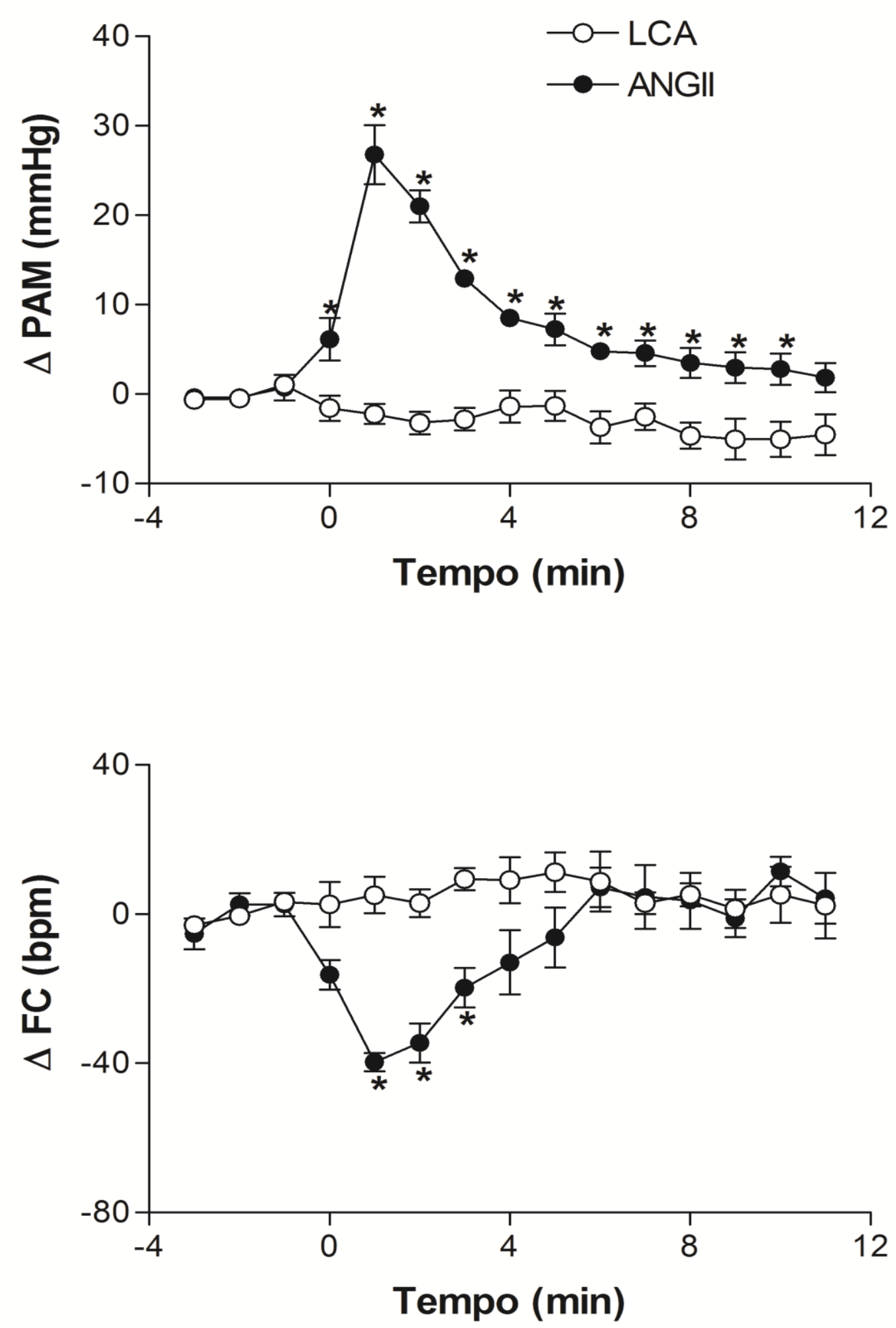

FIGURA 2 - Variação da pressão arterial media ( $\triangle P A M)$ e frequência cardíaca $(\triangle F C)$ ao longo do tempo após microinjeção de ANGll 0,4 nmol/100 nL (círculos pretos) ou $100 \mathrm{~nL}$ de LCA (círculos brancos) no PL. As injeções de ANGII ou LCA foram feitas no tempo 0 . Pontos representam as médias e as barras o EPM, $n=5{ }^{\star} P<0,05$, twoway ANOVA, pós-teste de Bonferroni. 


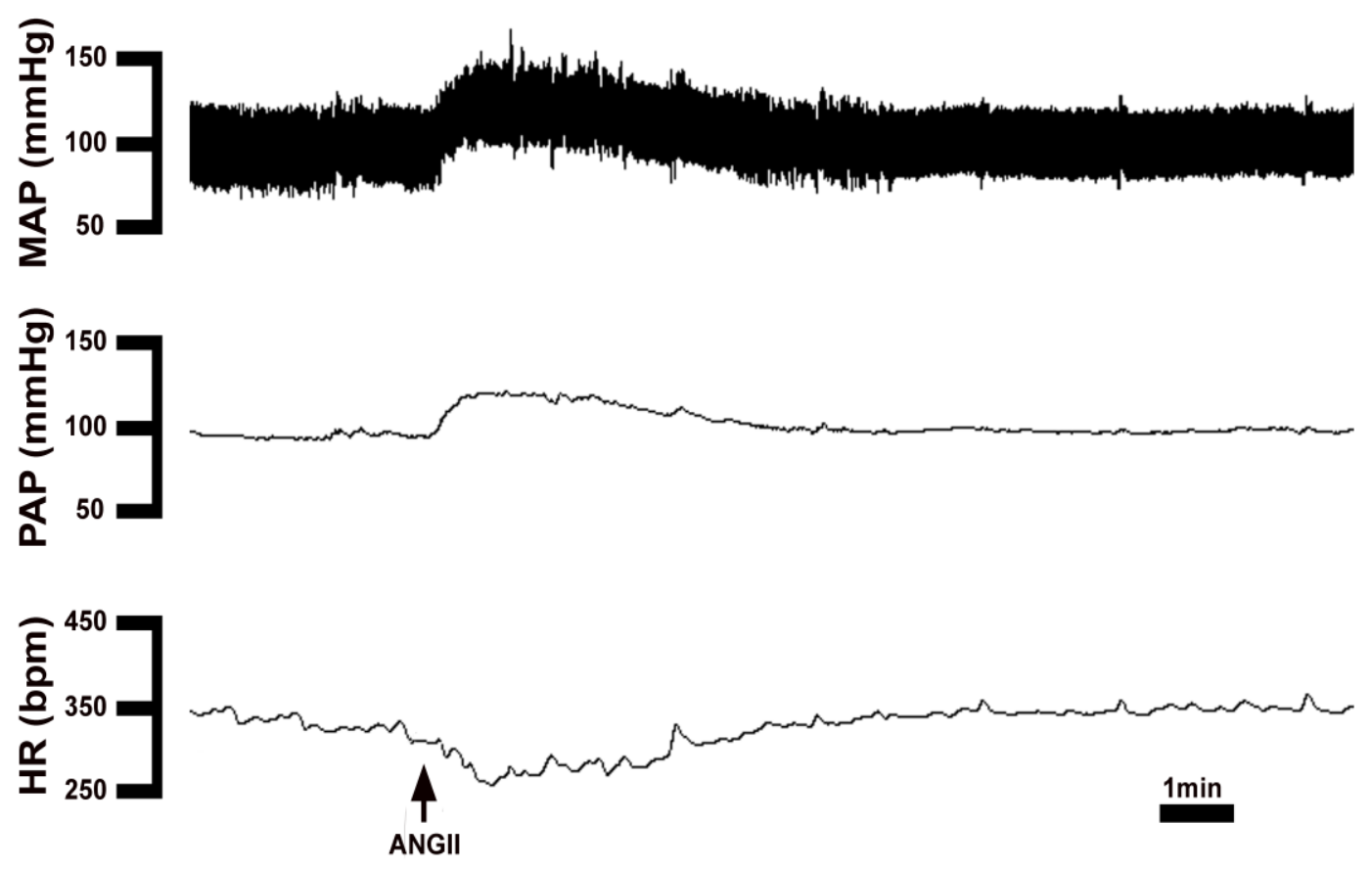

Figura 3. Registros representativos de um rato não anestesiado mostrando as alterações na pressão arterial pulsátil (PAP), pressão arterial média (PAM) e frequência cardíaca (FC) após microinjeção de ANGll 0,4nmol/100nL no PL.

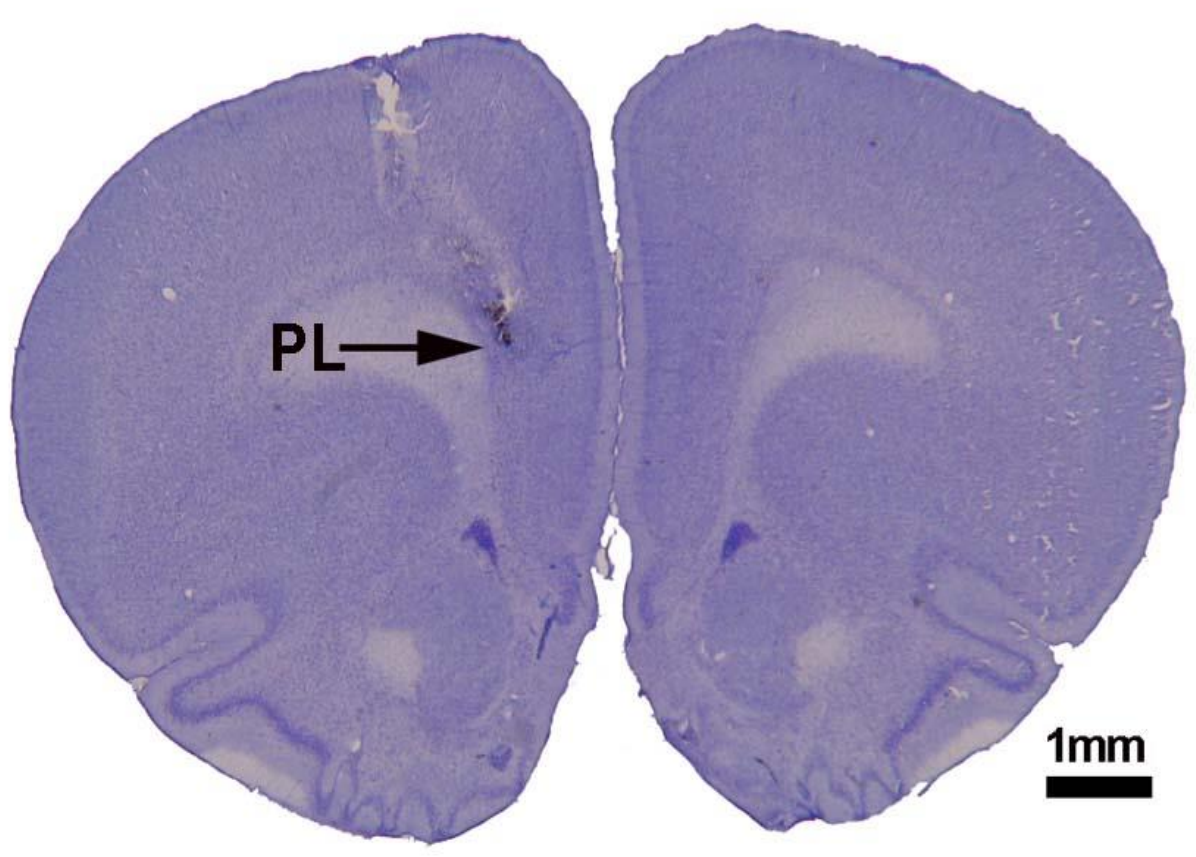

IA: $11.70 \mathrm{~mm}$

FIGURA 4 - A) Fotomicrografia representativa de uma secção coronal do cérebro de rato demonstrando o sítio da microinjeção de (ANGII) $0,4 \mathrm{nmol} / 100 \mathrm{~nL}$ no $\mathrm{PL}$, indicado pela seta. IA, interaural. 
2) Efeito da microinjeção de ANGIl em áreas fora do PL sobre a pressão arterial e frequência cardíaca de ratos

A microinjeção de $0,4 \mathrm{nmol} / 100 \mathrm{~nL}$ de ANGll em áreas fora do $\mathrm{PL}$, no cortex cingulado 1 (Cg1) não causou efeito sobre a PA ou FC. Os valores basais cardiovasculares antes e após a microinjeção de ANGll no Cg1 foram respectivamente: $\mathrm{PAM}=89.46 \pm 1.9$ vs $100.7 \pm 5.5 \mathrm{mmHg}, \mathrm{t}=2.0, \mathrm{P}>0,05$ e FC 377.9 \pm 21.8 vs $372.5 \pm 14.1 \mathrm{bpm}, \mathrm{t}=0.4, \mathrm{P}>0,05 ; \mathrm{n}=3$.

A figura 6 apresenta uma representação diagramática mostrando os sítios de microinjeção de ANGII no córtex cingulado 1. 


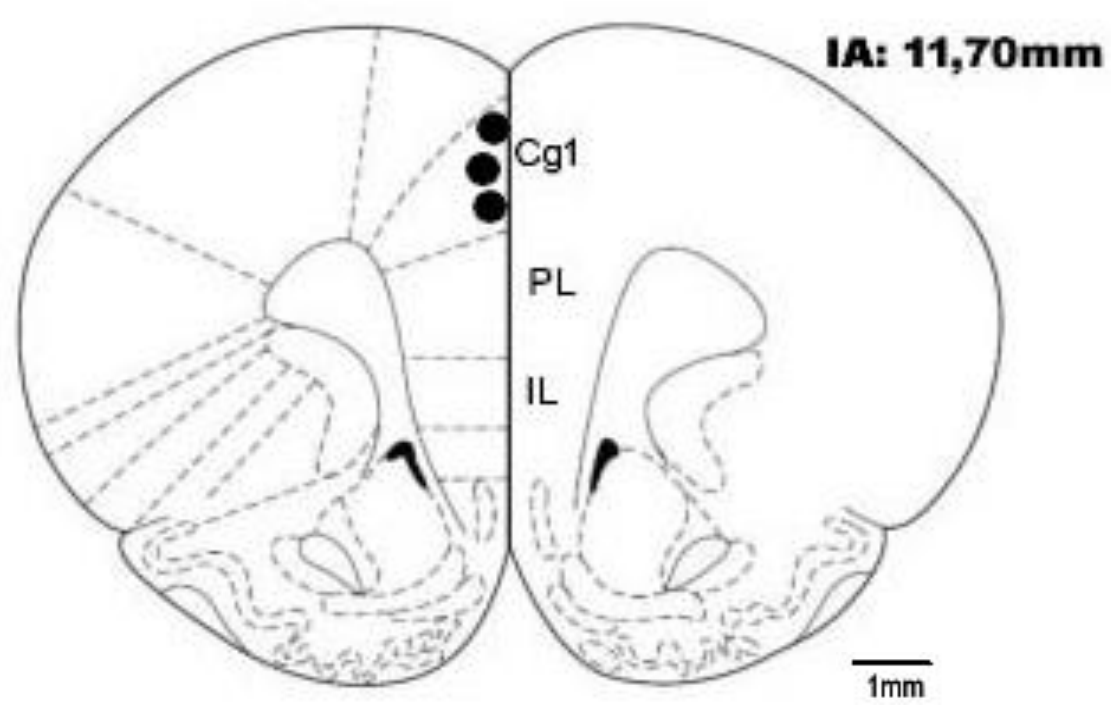

Figura 6. Diagrama do cérebro de rato baseado no atlas Paxinos e Watson (1997) mostrando os sítios de microinjeção de drogas nas áreas fora do PL. Os círculos pretos indicam locais de microinjeção de ANGll 0,4nmol/100nL (círculos pretos) no córtex cingulado ( $\mathrm{Cg} 1)$. IA, Interaural. 


\section{3) Efeito da administração periférica de veículo sobre as respostas} cardiovasculares à microinjeção de ANGII no PL de ratos.

A injeção de salina 0,9\% (1mL/Kg) por via endovenosa não causou alterações significativas na PAM (ANTES: $95.77 \pm 5.77 \mathrm{mmHg}$; APÓS: $97.55 \pm 6.62 \mathrm{mmHg}$, $\mathrm{t}=1.62$, teste $\mathrm{t}$ de student, $\mathrm{p}>$ 0,05) e FC (ANTES: $346.7 \pm 8.83$ bpm; APÓS: $347.1 \pm$ 9.99 bpm, $t=0.14 p>0.05, n=4)$.

A análise de two-way ANOVA não indicou efeito significante da salina $(0,9 \%)$

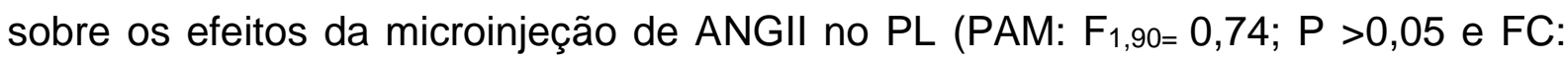
$F_{1,90=1,56 ;} P>0,05$ ), do tempo (PAM: $F_{14,90=15,05 ; P}>0,05$ e $F C: F_{14,90=8,40 ;} P$

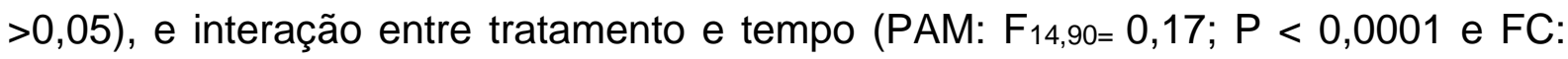
$\left.F_{14,90=0,49 ;} P<0,0001\right)$ (Figura 5) 

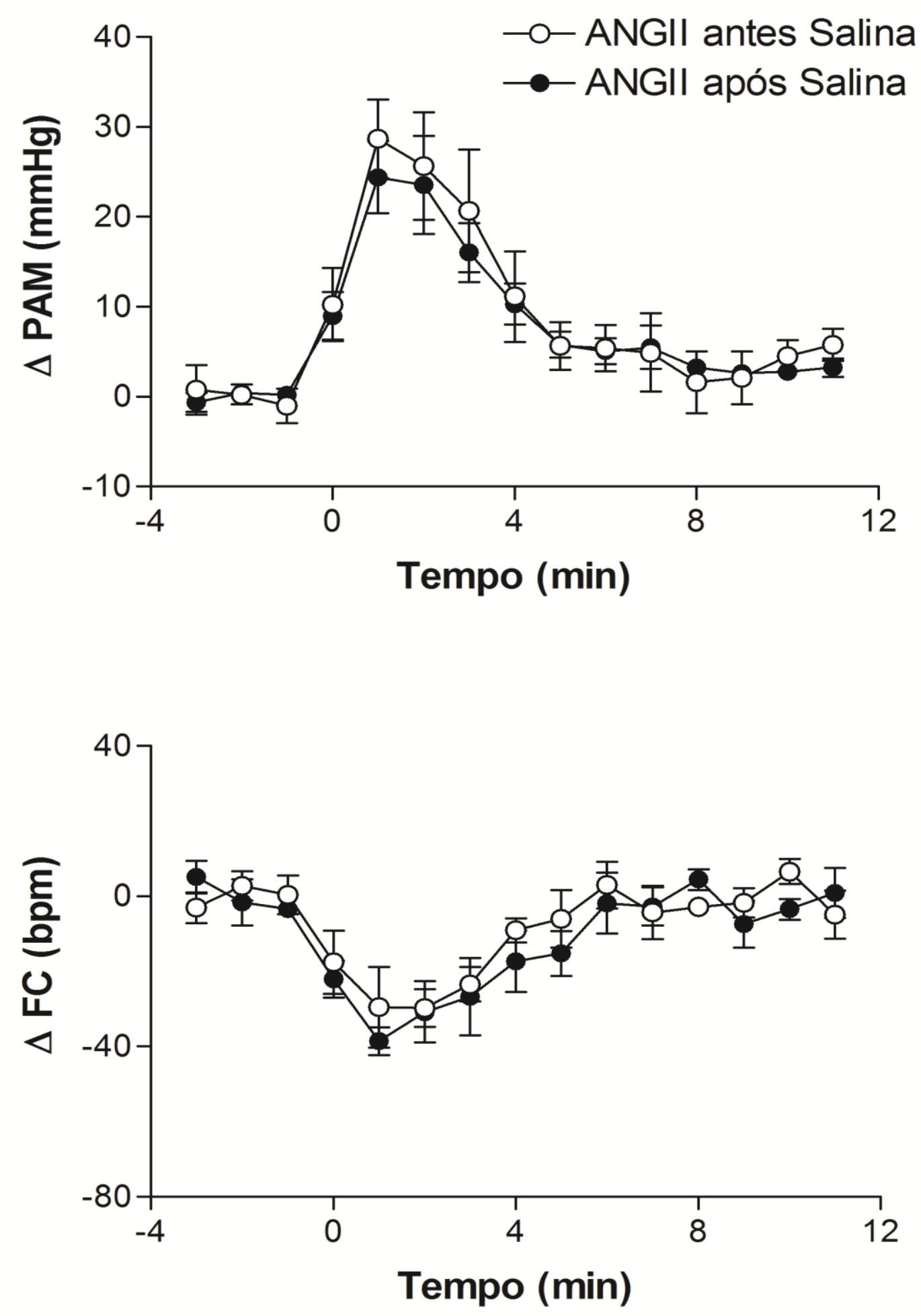

Figura 5. Variação da pressão arterial media $(\triangle P A M)$ e frequência cardíaca $(\triangle F C)$ ao longo do tempo após microinjeção de ANGll $(0,4 \mathrm{nmol} / 100 \mathrm{~nL})$ no $\mathrm{PL}$ antes (círculos brancos) e após (círculos pretos) injeção de salina (0,9\%). As microinjeções foram feitas no tempo 0 (zero). Os pontos representam as médias e as barras 0 EPM, $n=4,{ }^{*} P<0,05$, two-way ANOVA. 
4) Efeito da administração periférica de bloqueador ganglionar sobre as respostas cardiovasculares à microinjeção de ANGII no PL de ratos.

O pré-tratamento com o bloqueador ganglionar pentolínio $(5 \mathrm{mg} / \mathrm{kg})$ por via intravenosa causou redução na PAM basal (ANTES: $101.5 \pm 5.04 \mathrm{mmHg}$; APÓS: $73.56 \pm 3.63 \mathrm{mmHg} ; \mathrm{t}=2.03 ; \mathrm{p}<0,05$, teste t de Student, $\mathrm{n}=5$ ), mas não alterou a FC (ANTES: $375.9 \pm 10.80$ bpm; APÓS: $360.3 \pm 5.40$ bpm, $t=1.47 p>0,05$, test $t$ de Student, $n=5)$.

O pré-tratamento i.v com pentolínio bloqueou a resposta bradicardíaca, mas não foi observada alteração significativa na resposta pressora induzida pela

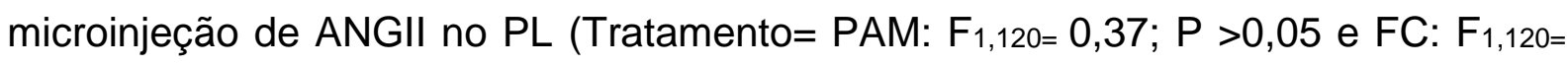
32,17; $\mathrm{P}<0.0001 ;$ Tempo= $\mathrm{PAM}: \mathrm{F}_{14,120}=29,24 ; \mathrm{P}<0,0001$ e FC: $\mathrm{F}_{14,120}=2,62 ; \mathrm{P}$ $<0,05$; Interação= PAM: $F_{14,120}=1,46 ; P>0,05$ e $F C: F_{14,120=1,87 ; ~} P<0,05$; two-way ANOVA, pós teste de Bonferroni), (Figura 6). 

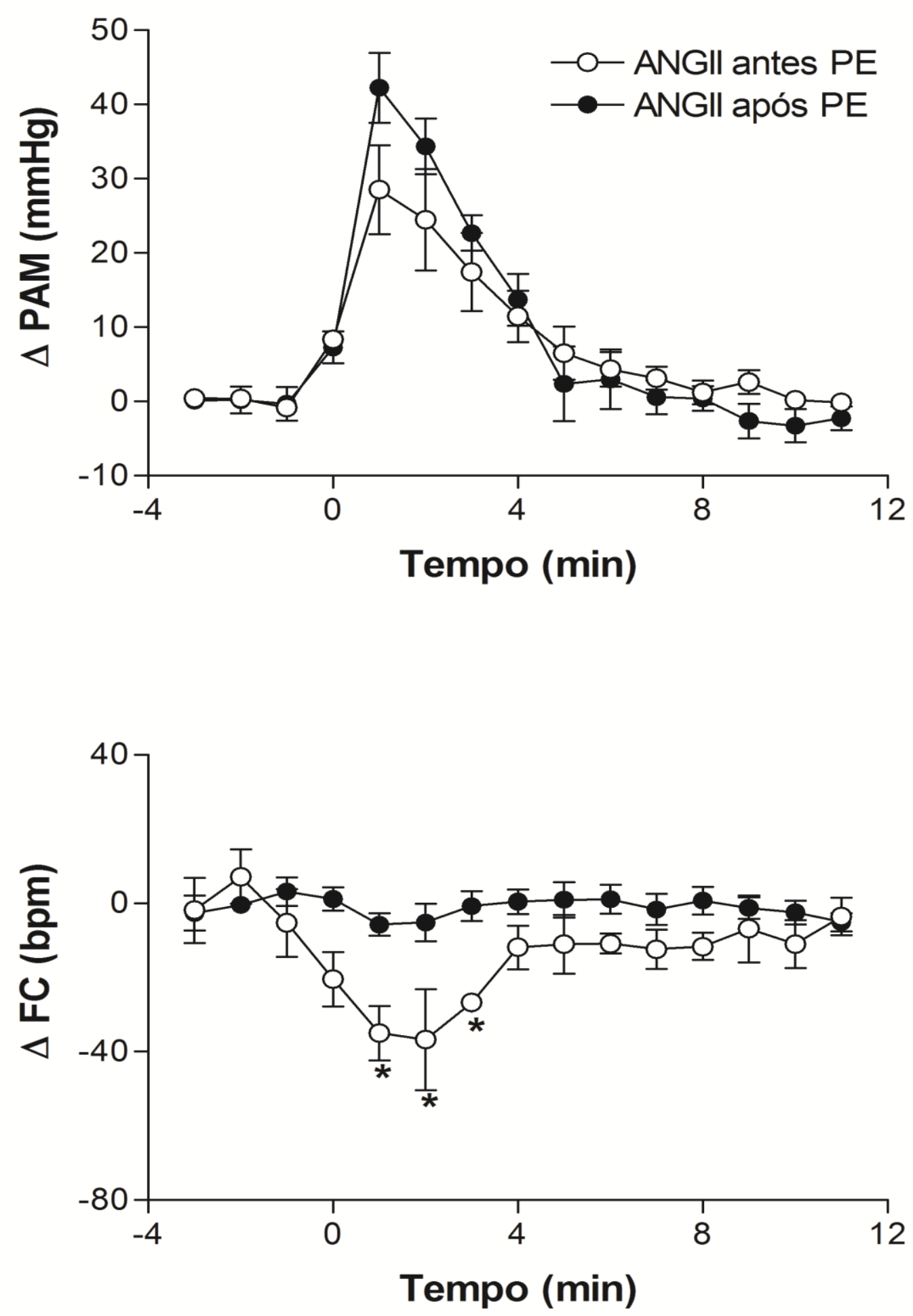

Figura 6. Variação da pressão arterial media $(\triangle \mathrm{PAM})$ e frequência cardíaca $(\triangle \mathrm{FC})$ ao longo do tempo após microinjeção de ANGll $(0,4 \mathrm{nmol} / 100 \mathrm{~nL})$ no $\mathrm{PL}$ antes (círculos brancos) e após (círculos pretos) o pré-tratamento com pentolínio (PE, 5 $\mathrm{mg} / \mathrm{kg}$ ). As microinjeções foram feitas no tempo 0 (zero). Os pontos representam as médias e as barras o EPM, $n=5,{ }^{*} P<0,05$, two-way ANOVA, pós-teste de Bonferroni. 


\section{5) Efeito da administração periférica de antagonista de receptores} vasopressinérgicos sobre as respostas cardiovasculares à microinjeção de

\section{ANGIl no PL de ratos}

A injeção intravenosa de dTyr(CH2)5(Me)AVP $(50 \mu \mathrm{g} / \mathrm{kg})$, antagonista seletivo dos receptores vasopressinérgicos $\mathrm{V} 1$, não causou alterações significativas nos valores basais da PAM (ANTES:96.83 $\pm 2.37 \mathrm{mmHg}$; APÓS:99.74 $\pm 2.91 \mathrm{mmHg}$; $\mathrm{t}=3.06 ; \mathrm{P}>$ 0,05; test de Student pareado, $\mathrm{n}=6$ ) e na FC (ANTES:381.1 $\pm 16.17 \mathrm{bpm}$; APÓS:379.7 \pm 18.17 bpm; $t=0.34 ; P>0,05 ;$ test $t$ de Student pareado, $n=6)$ de ratos não anestesiados.

O pré-tratamento i.v com dTyr(CH2)5(Me)AVP bloqueou a resposta pressora a resposta bradicardíaca induzida pela microinjeção de ANGll no PL (Tratamento = PAM: $F_{1,150=39,28 ; ~} P<0,0001$ e $F C: F_{1,150=4,07 ; ~} P<0,05 ;$ Tempo $=$ PAM: $F_{14,150=}$ 3,16; $P<0,05$ e FC: $F_{14,150=2,42 ; ~}<<0,05 ;$ Interação = PAM: $F_{14,150=2,80 ;} P<0,05$ e

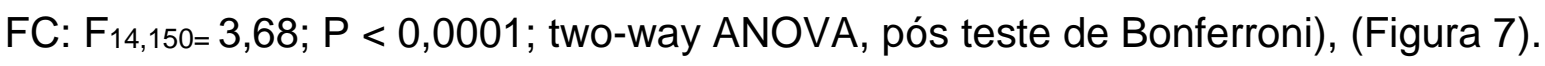

A figura 8 mostra os diagramas representativos modificados do atlas de Paxinos e Watson (1997) indicando os sítios de microinjeção de ANGll no PL dos animais tratados perifericamente com Salina, Pentolínio e dTyr(CH2)5(Me)AVP. 

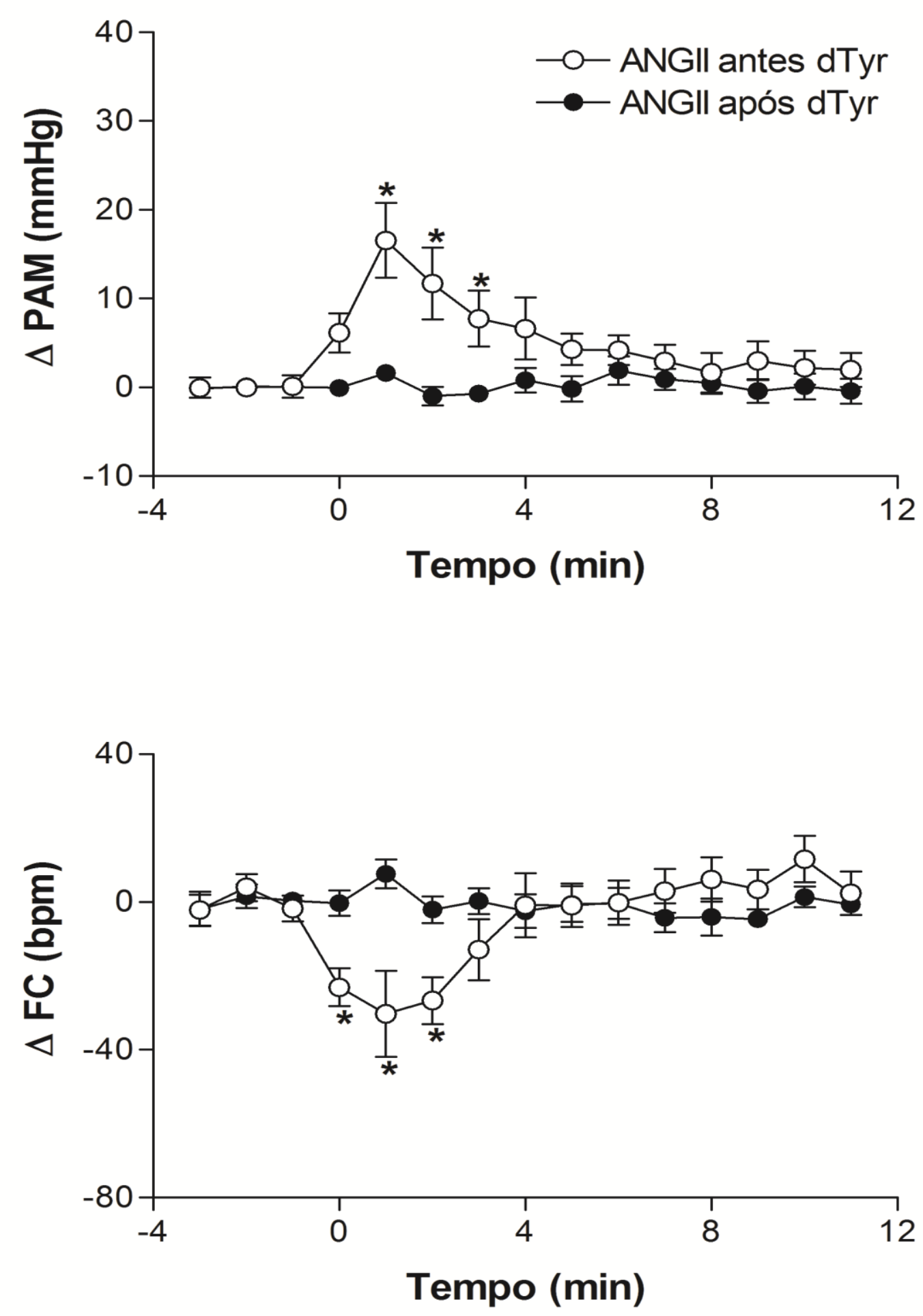

Figura 7. Variação da pressão arterial media $(\triangle \mathrm{PAM})$ e frequência cardíaca $(\triangle \mathrm{FC})$ ao longo do tempo após microinjeção de ANGII $(0,4 \mathrm{nmol} / 100 \mathrm{~nL})$ no $\mathrm{PL}$ antes (círculos brancos) e após (círculos pretos) o pré-tratamento com dTyr(CH2)5(Me)AVP $(50 \mu \mathrm{g} / \mathrm{kg})$. As microinjeções foram feitas no tempo 0 (zero). Os pontos representam as médias e as barras o EPM, $n=6$, ${ }^{*} P<0,05$, two-way ANOVA, pós-teste de Bonferroni. 

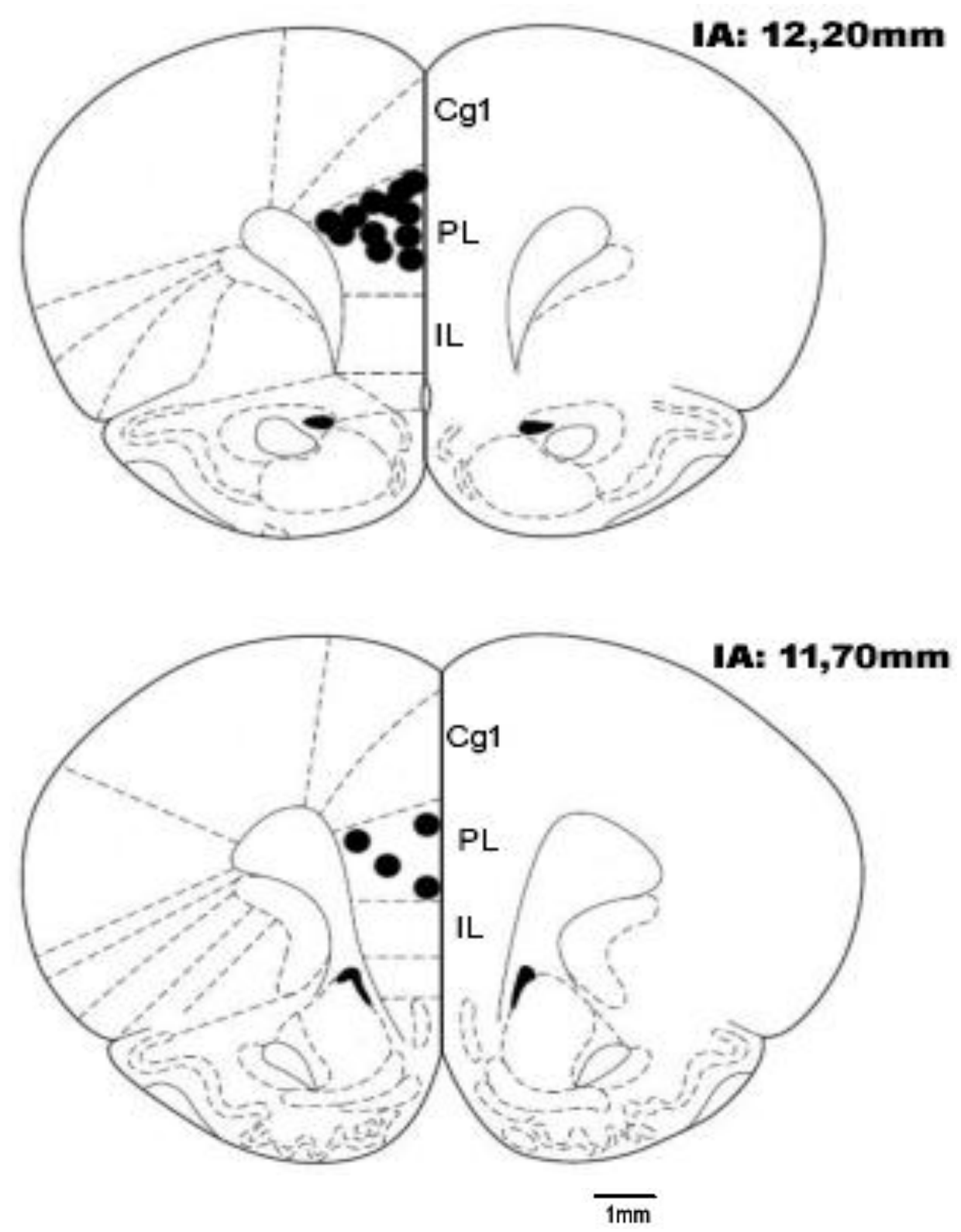

FIGURA 8 - Diagrama do cérebro de rato baseado no atlas Paxinos e Watson (1997) mostrando os sítios de microinjeção de drogas no $\mathrm{PL}$ dos animais tratados perifericamente com Salina (0,9\%), Pentolínio, dTyr(CH2)5(Me)AVP. 


\section{6) Efeito da microinjeção de LCA no PL sobre as respostas cardiovasculares à} microinjeção local de ANGII

A microinjeção de líquido cefalorraquidiano artificial (LCA) 100nL no PL não causou alterações significativas na PAM (ANTES: $105.9 \pm 5.71 \mathrm{mmHg}$; APÓS: 106.5 $\pm 5.50 \mathrm{mmHg} ; \mathrm{t}=0.56 ; \mathrm{P}>0,05$; test de Student pareado, $\mathrm{n}=4$ ) e na frequência cardíaca (ANTES: $367.1 \pm 0.40$ bpm; APÓs: $369.9 \pm 3.45$ bpm; t=0.79; P > 0,05; test t de Student pareado, $\mathrm{n}=4$ ) de ratos não anestesiados.

O pré-tratamento local com líquido cefalorraquidiano artificial (LCA) não alterou a resposta pressora e bradicardíaca causada pela administração de ANGII

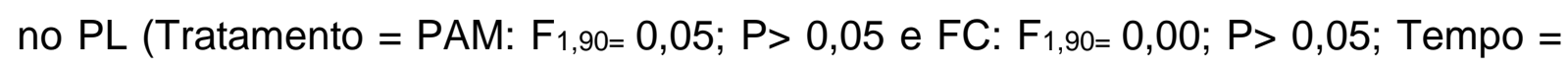

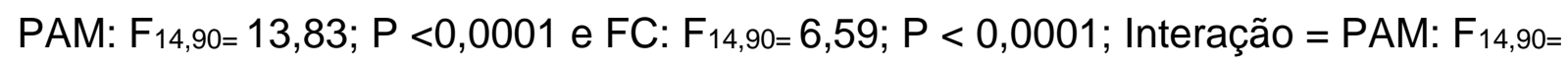

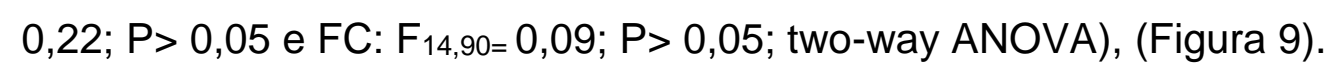



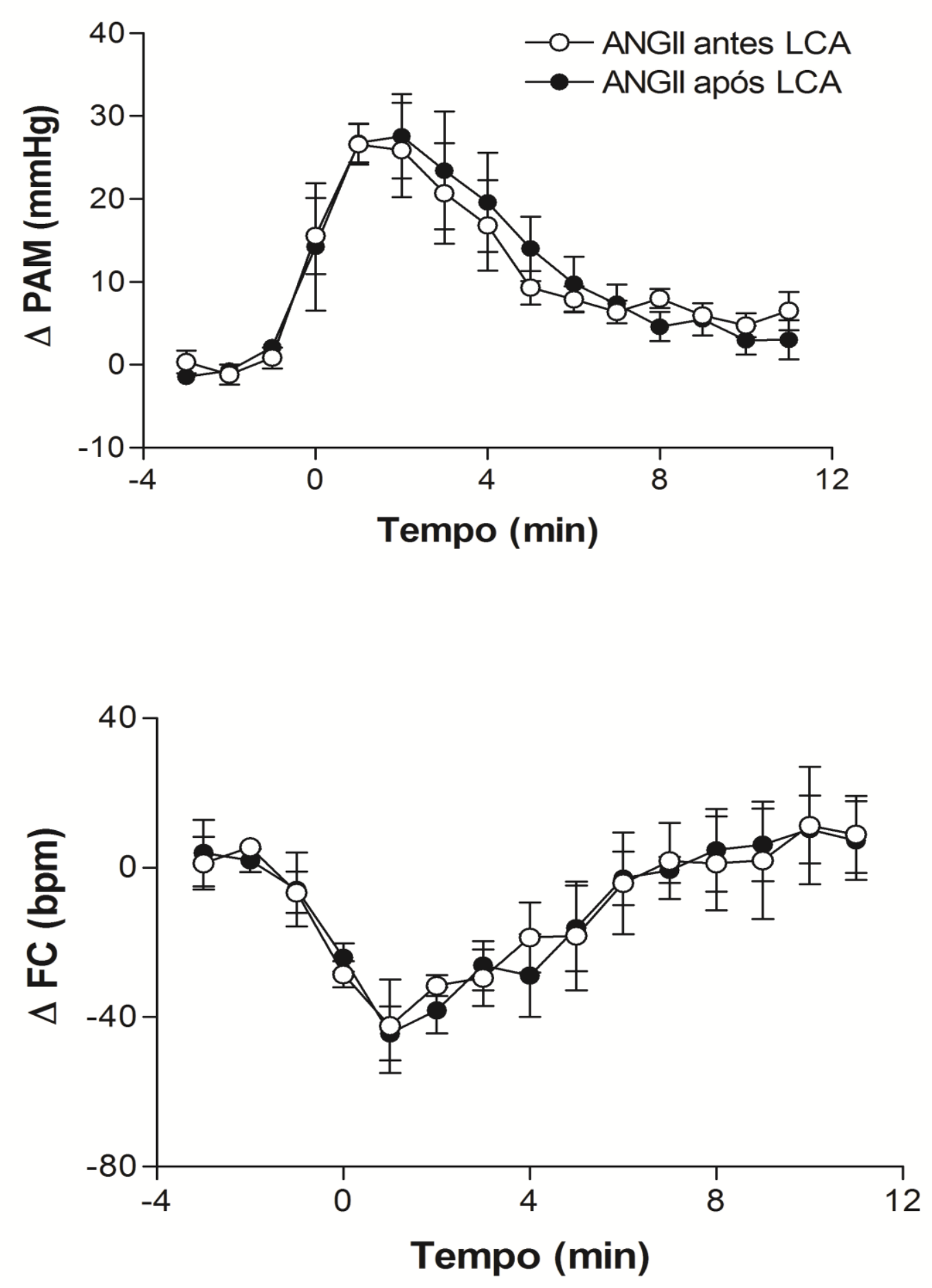

Figura 9. Variação da pressão arterial media $(\triangle \mathrm{PAM})$ e frequência cardíaca $(\triangle \mathrm{FC})$ ao longo do tempo após microinjeção de ANGIl $(0,4 \mathrm{nmol} / 100 \mathrm{~nL})$ no $\mathrm{PL}$ antes (círculos brancos) e após (círculos pretos) LCA (100nL). As microinjeções foram feitas no tempo (zero). Os pontos representam as médias e as barras o EPM, $n=4$, ${ }^{*} \mathrm{P}<0,05$, two-way ANOVA. 


\section{7) Efeito da microinjeção de antagonista do receptor $\mathrm{AT}_{1}$ no $\mathrm{PL}$ sobre as respostas cardiovasculares à microinjeção local de ANGII}

A microinjeção de Candesartan $(0,03 \mathrm{nmol} / 100 \mathrm{~nL})$ antagonista seletivo dos receptores $A T 1$, no PL não causou alterações significativas nos valores basais de PA (ANTES: $101.7 \pm 1.42 \mathrm{mmHg}$; APÓS: $100.5 \pm 1.04 \mathrm{mmHg} ; \mathrm{t}=2.08 ; \mathrm{P}>0,05$; test de Student pareado, $n=5$ ) e FC (ANTES: $381.3 \pm 22.10$ bpm; APÓS: $385.1 \pm 22.40$ bpm; $t=0.65 ; P>0,05$; test $t$ de Student pareado, $n=5$ ) de ratos não anestesiados.

O pré-tratamento local com candersatan $(0,03 \mathrm{nmol} / 100 \mathrm{~nL})$ atenuou a resposta pressora (Antes: $\triangle \mathrm{PAM}=16.11 \pm 2.6$; Após: $\triangle \mathrm{PAM}=8.077 \pm 1.7 \mathrm{mmHg}$; $\mathrm{t}=7.245, \mathrm{p}=0.001$; teste $\mathrm{T}$ de Student pareado) e a resposta bradicardíaca causada pela administração de ANGll no PL (Antes: $\triangle \mathrm{FC}=-22.56 \pm 6.1$; Após: $\Delta \mathrm{FC}=-6.526 \pm$ 5.3 bpm; $t=5.455, p=0.005$; teste $T$ de Student pareado) (figura 12). Comparando as respostas causadas pela administração de ANGll no PL antes e após o prétratamento local com candesartan $(0,03 \mathrm{nmol} / 100 \mathrm{~nL})$, observamos que houve um efeito no tratamento (PAM: $F_{1,120=15,87 ; P}=0,0001$ e $F C: F_{1,120=0,16 ;} P>0,05$ ); no tempo (PAM: $F_{14,120=7,19 ;} P<0,0001$ e $F C: F_{14,120=2,33 ; ~} P<0,05$ ); porém não houve

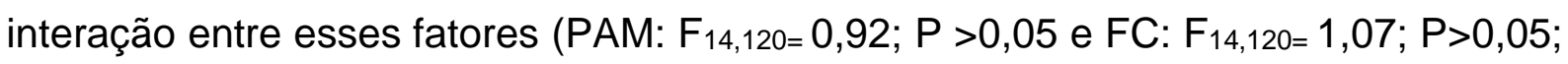
two-way ANOVA, pós teste de Bonferroni) (Figura 10). 

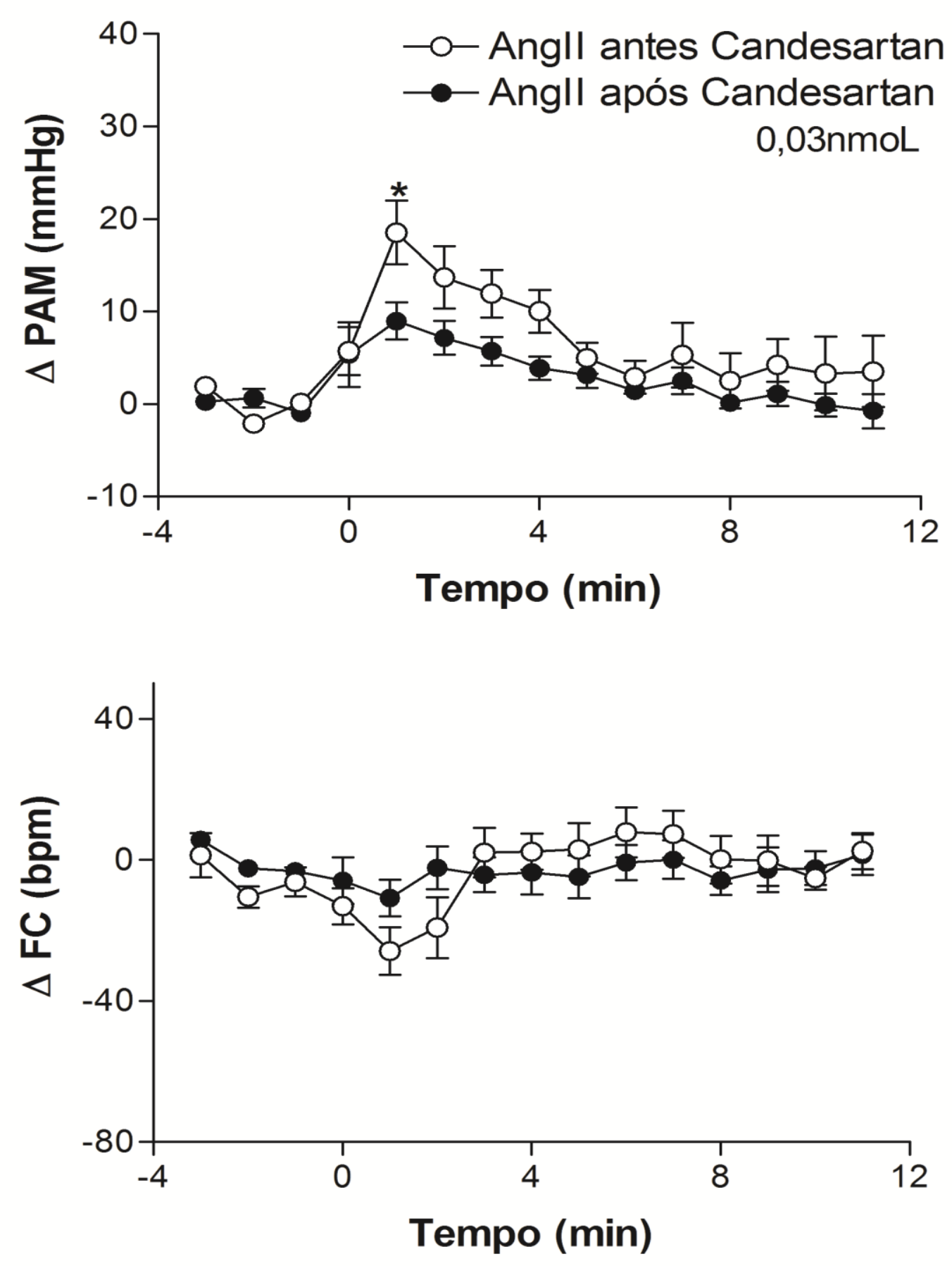

Figura 10. Variação da pressão arterial media $(\triangle P A M)$ e frequência cardíaca $(\triangle F C)$ ao longo do tempo após microinjeção de ANGII $(0,4 \mathrm{nmol} / 100 \mathrm{~nL})$ no $\mathrm{PL}$ antes (círculos brancos) e após (círculos pretos) o pré-tratamento com Candesartan $(0,03 \mathrm{nmol} / 100 \mathrm{~nL})$. As microinjeções foram feitas no tempo (zero). Os pontos representam as médias e as barras o EPM, $n=5$, ${ }^{*} P<0,05$, two-way ANOVA, pósteste de Bonferroni. 
A microinjeção de Candesartan $(0,1 \mathrm{nmol} / 100 \mathrm{~nL})$ antagonista seletivo dos receptores AT1, no PL não causou alterações significativas nos valores basais de PA (ANTES: $100.7 \pm 1.98 \mathrm{mmHg}$; APÓS: $99.80 \pm 2.05 \mathrm{mmHg} ; \mathrm{t}=1.27 ; \mathrm{P}>0,05$; test de Student pareado, $\mathrm{n}=6$ ) e FC (ANTES: $367.0 \pm 5.20$ bpm; APÓS: $366.3 \pm 5.65$ bpm; $t=0.17 ; P>0,05$; test $t$ de Student pareado, $n=6$ ) de ratos não anestesiados.

O pré-tratamento local com candersatan $(0,1 \mathrm{nmol} / 100 \mathrm{~nL})$ bloqueou a resposta pressora (Antes: $\triangle \mathrm{PAM}=19.79 \pm 2.0$; Após: $\triangle \mathrm{PAM}=3.017 \pm 1.3 \mathrm{mmHg} ; \mathrm{t}=7.89$, $\mathrm{p}=0.0005$; teste $\mathrm{T}$ de Student pareado) e a resposta bradicardíaca causada pela administração de ANGll no $\mathrm{PL}$ (Antes: $\triangle \mathrm{FC}=-36.24 \pm 8.9$; Após: $\Delta \mathrm{FC}=-3.424 \pm$ 5.2bpm; $\mathrm{t}=2.9, \mathrm{p}=0.03$; teste $\mathrm{T}$ de Student pareado) (Figura 12). Comparando as respostas causadas pela administração de ANGll no PL antes e após o prétratamento local com candesartan $(0,1 \mathrm{nmol} / 100 \mathrm{~nL})$, observamos que houve um

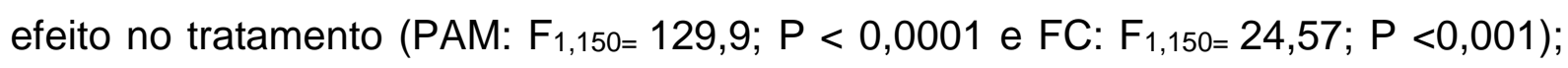

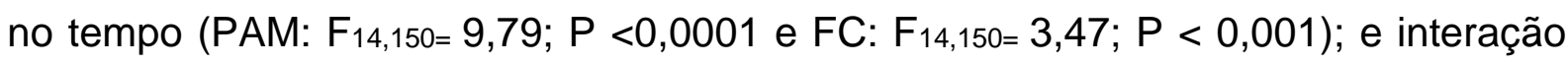
entre esses fatores (PAM: $F_{14,150=5,64 ;} P<0,0001$ e FC: $F_{14,150=1,46 ;} P>0,05$; twoway ANOVA, pós teste de Bonferroni) (Figura 11) 

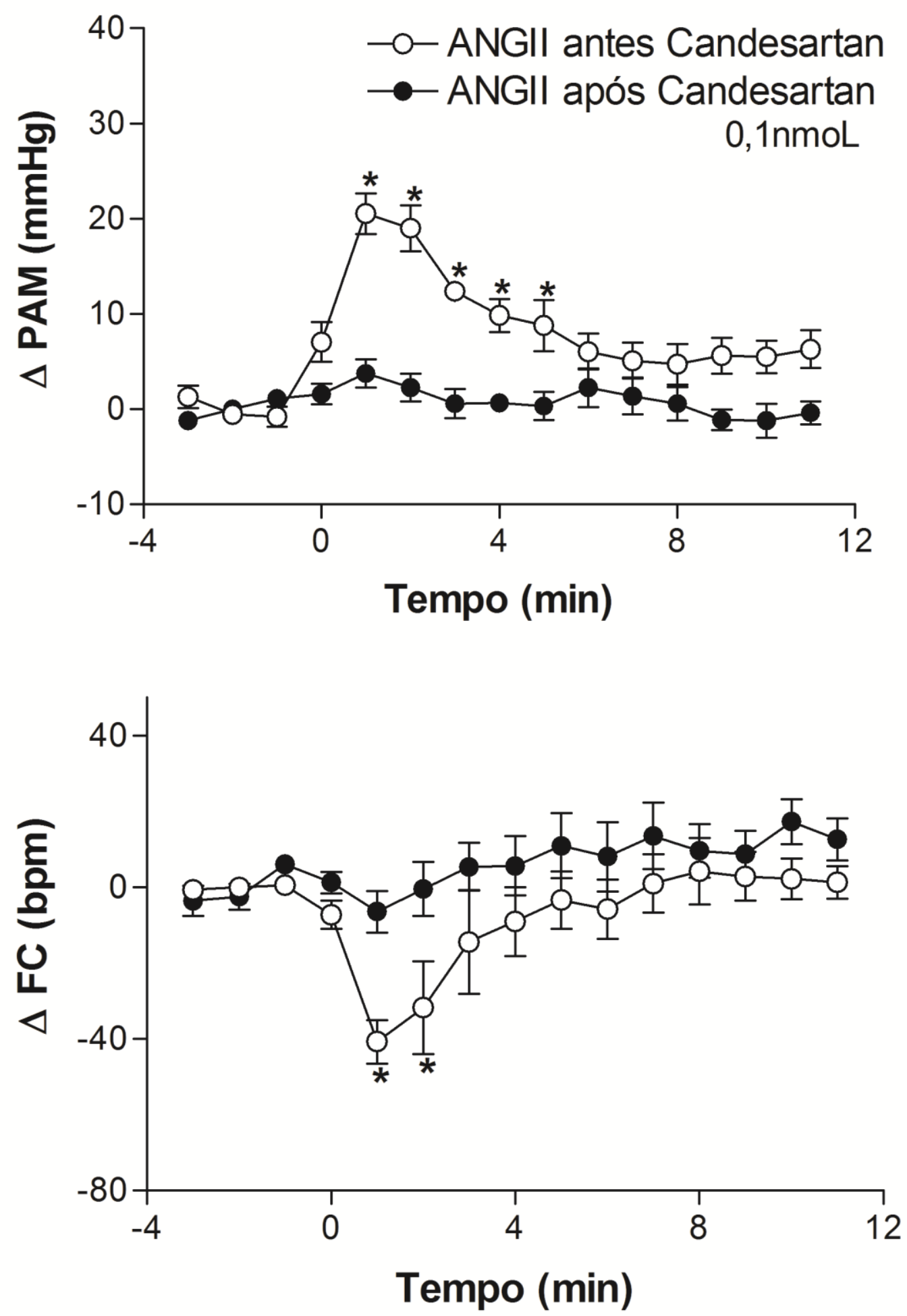

Figura 11. Variação da pressão arterial media $(\triangle \mathrm{PAM})$ e frequência cardíaca $(\triangle \mathrm{FC})$ ao longo do tempo após microinjeção de ANGII $(0,4 \mathrm{nmol} / 100 \mathrm{~nL})$ no $\mathrm{PL}$ antes (círculos brancos) e após (círculos pretos) o pré-tratamento com Candesartan $(0,1 \mathrm{nmol} / 100 \mathrm{~nL})$. As microinjeções foram feitas no tempo (zero). Os pontos representam as médias e as barras o EPM, $n=6,{ }^{*} P<0,05$, two-way ANOVA, pósteste de Bonferroni. 


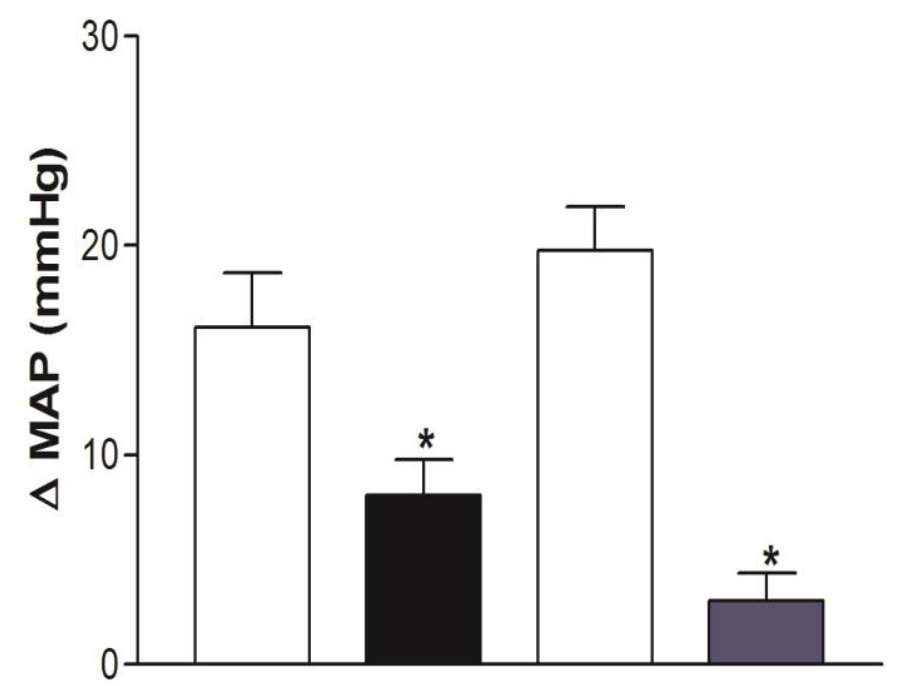

$\square$ Angll

Candesartan 0,03nmoL

$\square$ Candesartan $0,1 \mathrm{nmoL}$

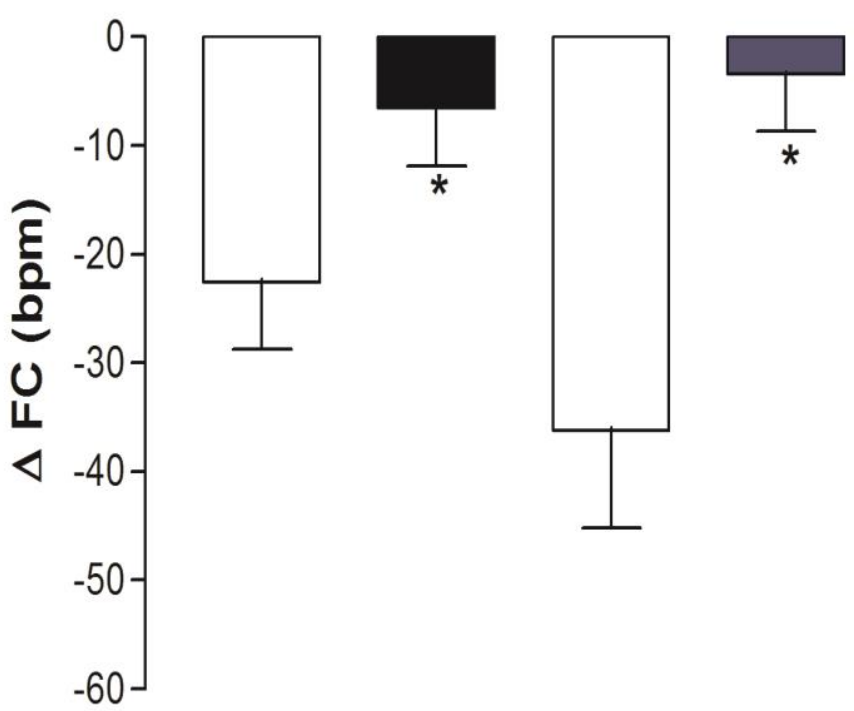

Figura 12. Efeito da microinjeção de $0,4 \mathrm{nmoL}$ de Angll no PL antes (colunas abertas) e depois (colunas pretas) Candesartan 0,03nmoL/100nL ( $\triangle \mathrm{PAM}, \mathrm{t}=7.245$, $\mathrm{p}=0.001 ; \quad \Delta \mathrm{FC}, \mathrm{t}=5.455, \quad \mathrm{p}=0.005 ; \mathrm{n}=5$ ), e (colunas azuis) Candesartan $0,01 \mathrm{nmoL} / 100 \mathrm{~nL}(\triangle \mathrm{PAM}, \mathrm{t}=7.89, \mathrm{p}=0.0005 ; \Delta \mathrm{FC}, \mathrm{t}=2.9, \mathrm{p}=0.03 ; \mathrm{n}=6)$ em ratos não anestesiados. As colunas representam as médias e as barras o erro padrão da média; ${ }^{*} \mathrm{P}<0.05$, test t de Student pareado. 


\section{8) Efeito da microinjeção de antagonista do receptor $\mathrm{AT}_{2}$ CGP42112A no PL} sobre as respostas cardiovasculares à microinjeção local de ANGII

A microinjeção central de CGP42112A (1nmol/100nL), antagonista seletivo de receptores $A T_{2}$, não causou alterações significativas nos valores basais da PAM (ANTES: $108.8 \pm 5.492 \mathrm{mmHg}$; APÓS: $102.9 \pm 5.84 \mathrm{mmHg}$; $\mathrm{t}=0.69$; $\mathrm{P}>0,05$; test de Student pareado, $n=6$ ) e na frequência cardíaca (ANTES: $371.1 \pm 10.67$ bpm; APÓS: $367.9 \pm 11.86$ bpm; $t=0.55 ; P>0,05$; test $t$ de Student pareado, $n=6$ ) de ratos não anestesiados.

O pré-tratamento local com CGP42112A (1nmol/100nL) atenuou a resposta pressora (Antes: $\triangle \mathrm{PAM}=18.36 \pm 2.5$; Após: $\triangle \mathrm{PAM}=7.731 \pm 1.8 \mathrm{mmHg} ; \mathrm{t}=4.33$, $\mathrm{p}=0.007$; teste $\mathrm{T}$ de Student pareado) e bradicardíaca induzida pela administração de ANGII no PL (Antes: $\Delta \mathrm{FC}=-42.46 \pm 6.8$; Após: $\Delta \mathrm{FC}=-12.79 \pm 6.1 \mathrm{bpm} ; \mathrm{t}=3.36$, $\mathrm{p}=0.01$; teste $\mathrm{T}$ de Student pareado) (Figura 15). Comparando as respostas causadas pela administração de ANGIl no PL antes e após o pré-tratamento local com CGP42112A ( $1 \mathrm{nmol} / 100 \mathrm{~nL})$, observamos que houve um efeito no tratamento

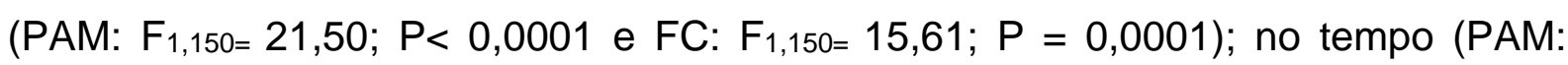
$F_{14,150=10,23 ;} P<0,0001$ e $\left.F C: F_{14,150=5,34 ; ~}<<0,0001\right)$; com interação entre esses

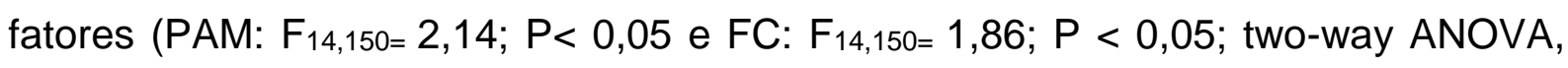
pós teste de Bonferroni), (Figura 13). 

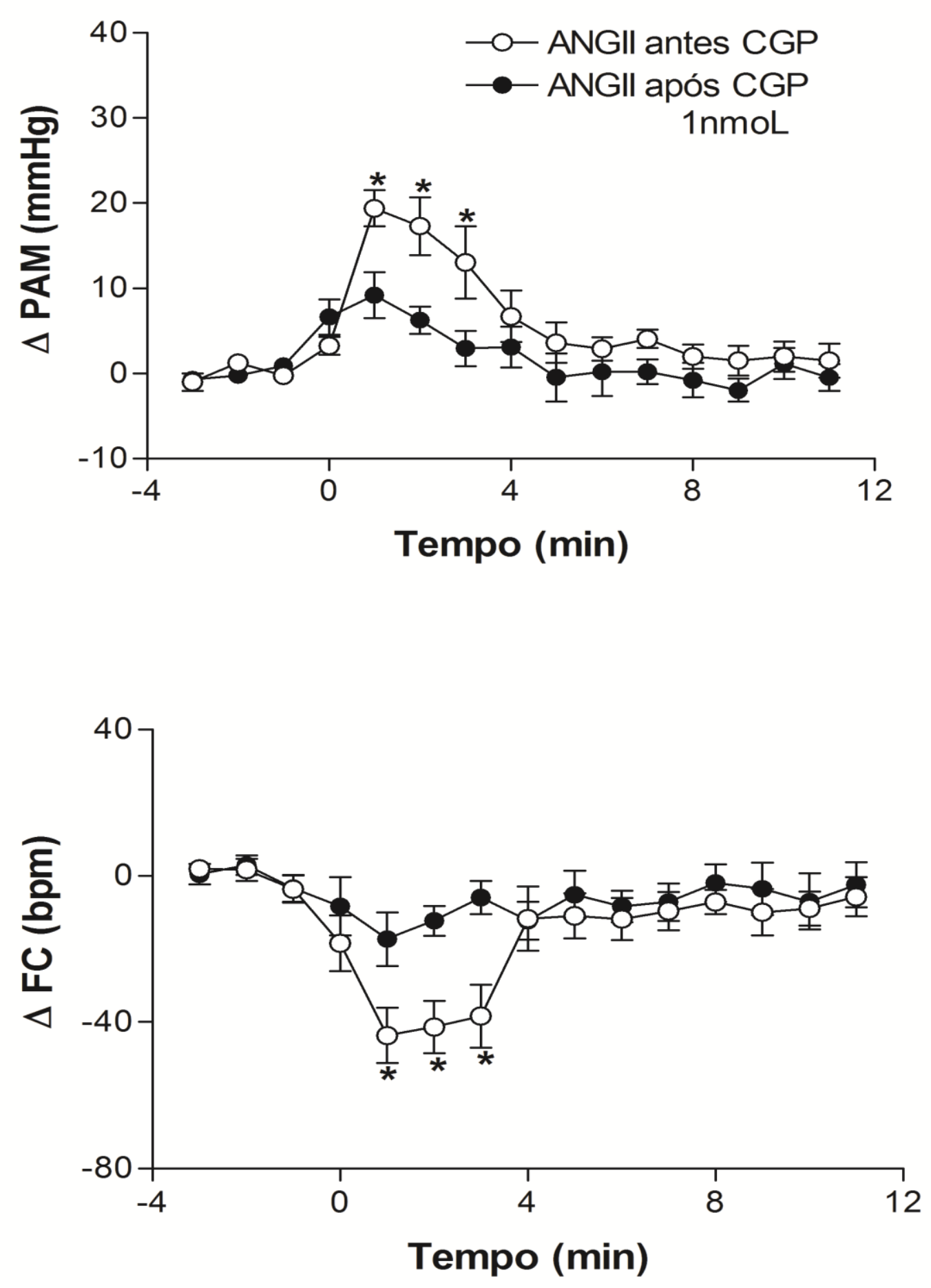

Figura 13. Variação da pressão arterial media $(\triangle \mathrm{PAM})$ e frequência cardíaca $(\triangle \mathrm{FC})$ ao longo do tempo após microinjeção de ANGll $(0,4 \mathrm{nmol} / 100 \mathrm{~nL})$ no $\mathrm{PL}$ antes (círculos brancos) e após (círculos pretos) o pré-tratamento com CGP42112A $(1 \mathrm{nmol} / 100 \mathrm{~nL})$. As microinjeções foram feitas no tempo (zero). Os pontos representam as médias e as barras o EPM, $n=6,{ }^{*} P<0,05$, two-way ANOVA, pósteste de Bonferroni 
A microinjeção central de CGP42112A (10nmol/100nL), antagonista seletivo de receptores $\mathrm{AT}_{2}$, não causou alterações significativas nos valores basais da PAM (ANTES: $105.7 \pm 2.10 \mathrm{mmHg}$; APÓS: $105.1 \pm 2.66 \mathrm{mmHg} ; \mathrm{t}=0.71 ; \mathrm{P}>0,05$; test de Student pareado, $n=5$ ) e na frequência cardíaca (ANTES: $377.5 \pm 12.33$ bpm; APÓS: $376.1 \pm 15.55$ bpm; $t=0.23 ; P>0,05 ;$ test $t$ de Student pareado, $n=5$ ) de ratos não anestesiados.

O pré-tratamento local com CGP42112A (10nmol/100nL) atenuou a resposta pressora (Antes: $\triangle \mathrm{PAM}=18.04 \pm 3.5$; Após: $\triangle \mathrm{PAM}=5.236 \pm 1.8 \mathrm{mmHg} ; \mathrm{t}=3.92$, $\mathrm{p}=0.01$; teste $\mathrm{T}$ de Student pareado) e bradicardíaca induzida pela administração de ANGII no PL (Antes: $\triangle \mathrm{FC}=-33.63 \pm 4.0$; Após: $\Delta \mathrm{FC}=-5.214 \pm 2.6 \mathrm{bpm} ; \mathrm{t}=7.94$, $\mathrm{p}=0.001$; teste $\mathrm{T}$ de Student pareado) (Figura 15). Comparando as respostas causadas pela administração de ANGIl no PL antes e após o pré-tratamento local com CGP42112A (10nmol/100nL), observamos que houve um efeito no tratamento (PAM: $F_{1,120=} 45,64 ; P<0,0001$ e $\left.F C: F_{1,120=4,41 ; ~}<<0,05\right)$; no tempo = PAM: $F_{14,120=}$ 6,24; $P<0,0001$ e FC: $\left.F_{14,120}=5,22 ; P<0,0001\right)$; e interação entre esses fatores (PAM: $F_{14,120=2,28 ; ~} P_{<} 0,05$ e FC: $F_{14,120=2,90 ; ~}$ < 0,05; two-way ANOVA, pós teste de Bonferroni), (Figura 14). 

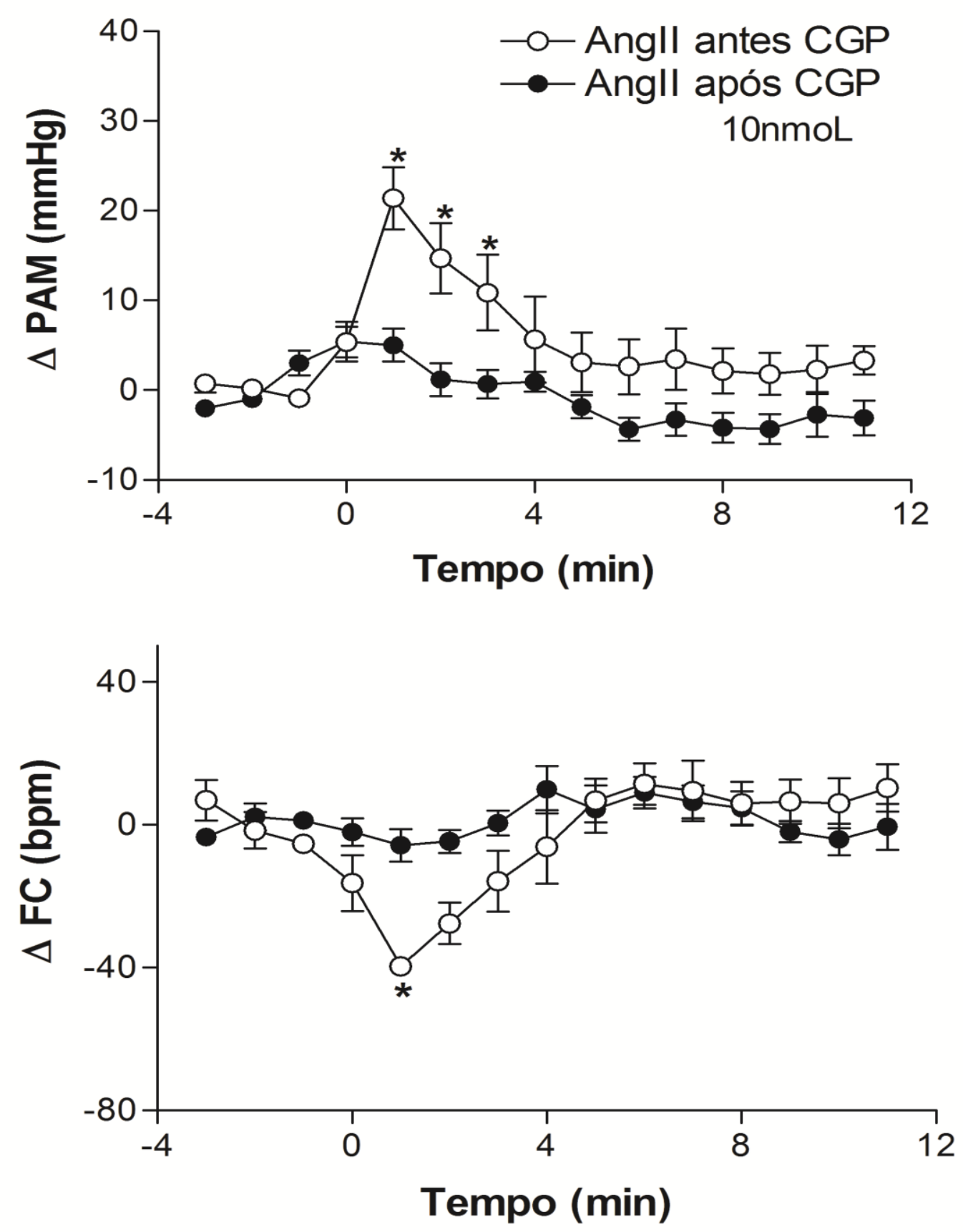

Figura 14. Variação da pressão arterial media $(\triangle P A M)$ e frequência cardíaca $(\triangle F C)$ ao longo do tempo após microinjeção de ANGll $(0,4 \mathrm{nmol} / 100 \mathrm{~nL})$ no $\mathrm{PL}$ antes (círculos brancos) e após (círculos pretos) o pré-tratamento com CGP42112A $(10 \mathrm{nmol} / 100 \mathrm{~nL})$. As microinjeções foram feitas no tempo (zero). Os pontos representam as médias e as barras o EPM, $n=5,{ }^{*} P<0,05$, two-way ANOVA, pósteste de Bonferroni. 

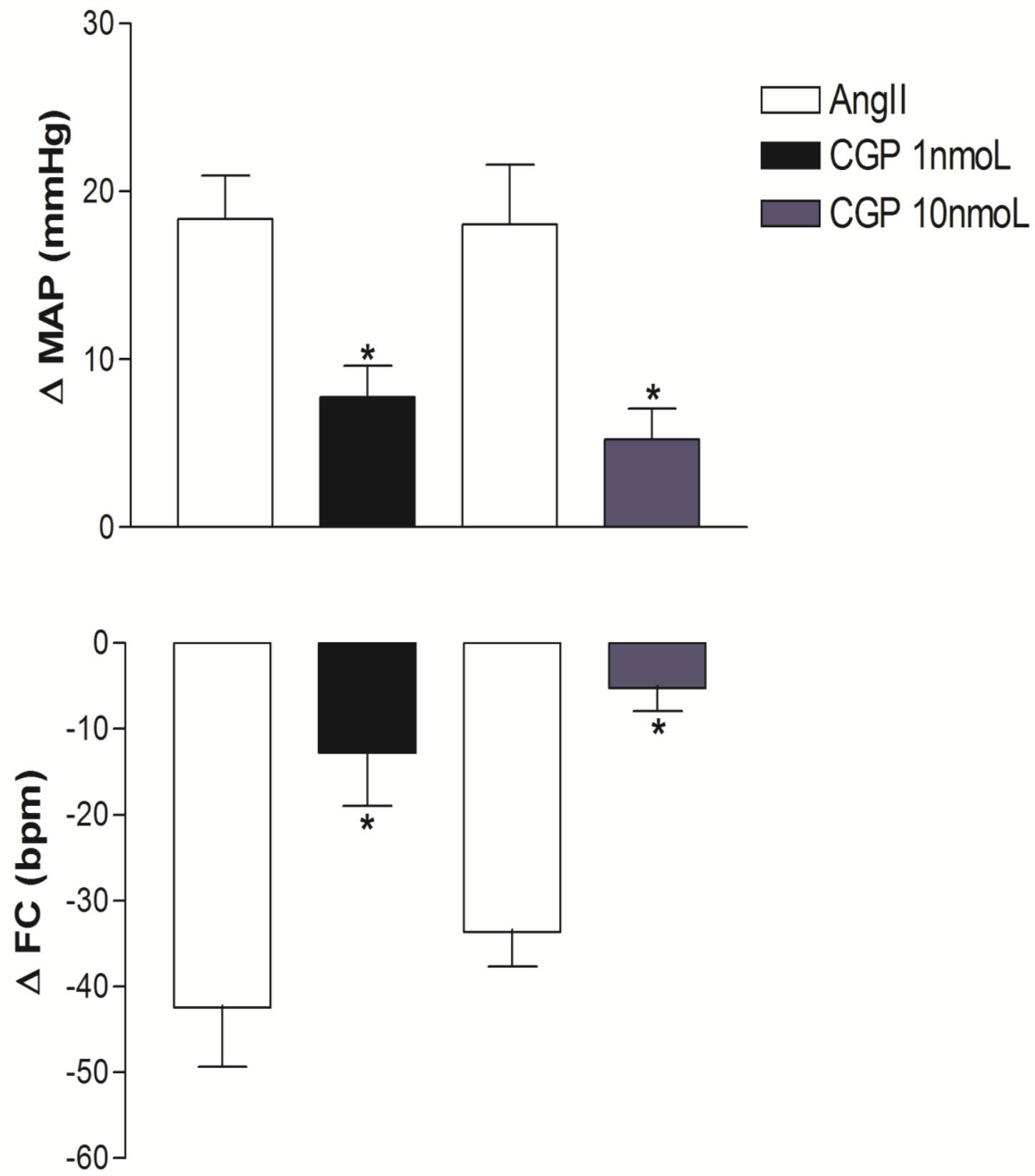

Figura 15. Efeito da microinjeção de $0,4 \mathrm{nmoL}$ de Angll no $\mathrm{PL}$ antes (colunas abertas) e depois (colunas pretas) CGP42112A $1 \mathrm{nmoL} / 100 \mathrm{~nL}$ ( $\triangle P A M, t=4.33$, $\mathrm{p}=0.007 ; \Delta \mathrm{FC}, \mathrm{t}=3.36, \mathrm{p}=0.01 ; \mathrm{n}=6$ ), e (colunas azuis) CGP42112A $10 \mathrm{nmoL} / 100 \mathrm{~nL}$ $(\triangle \mathrm{PAM} t=3.92, \mathrm{p}=0.01 ; \Delta \mathrm{FC}, \mathrm{t}=7.94, \mathrm{p}=0.001 ; \mathrm{n}=5)$ em ratos não anestesiados. As colunas representam as médias e as barras o erro padrão da média; ${ }^{*} \mathrm{P}<0.05$, test $\mathrm{t}$ de Student pareado. 
9) Efeito da microinjeção de antagonista do receptor AT2 PD 123319 no PL sobre as respostas cardiovasculares à microinjeção local de ANGII

A microinjeção central de PD 123319 (0,1nmol/100nL), antagonista seletivo de receptores $A T_{2}$, não causou alterações significativas nos valores basais da PAM (ANTES: $100.5 \pm 4.92 \mathrm{mmHg}$; APÓS: $102.6 \pm 5.32 \mathrm{mmHg}$; $\mathrm{t}=1.86 ; \mathrm{P}>0,05$; test de Student pareado, $n=6$ ) e na frequência cardíaca (ANTES: $370.4 \pm 13.26$ bpm; APÓS: $377.2 \pm 15.82 \mathrm{bpm} ; \mathrm{t}=0.97 ; \mathrm{P}>0,05 ;$ test $\mathrm{t}$ de Student pareado, $\mathrm{n}=6$ ) de ratos não anestesiados.

O pré-tratamento local com PD $123319(0,1 \mathrm{nmol} / 100 \mathrm{~nL})$ atenuou a resposta resposta pressora sem alterar a resposta bardicardíaca induzida pela administração de ANGII no PL (Tratamento = PAM: $F_{1,150=12,95 ;} P<0,05$ e FC: $F_{1,150=3,30 ; ~}$ > 0,05; Tempo = PAM: $F_{14,150=13,99 ;} P<0,0001$ e FC: $F_{14,150=4,24 ; ~}<<0,0001$; Interação $=$ PAM: $F_{14,150=2,80 ;} P_{<} 0,05$ e $F C: F_{14,150=0,58 ; ~}$ P 0,05; two-way ANOVA, pós teste de Bonferroni), (Figura 16). 

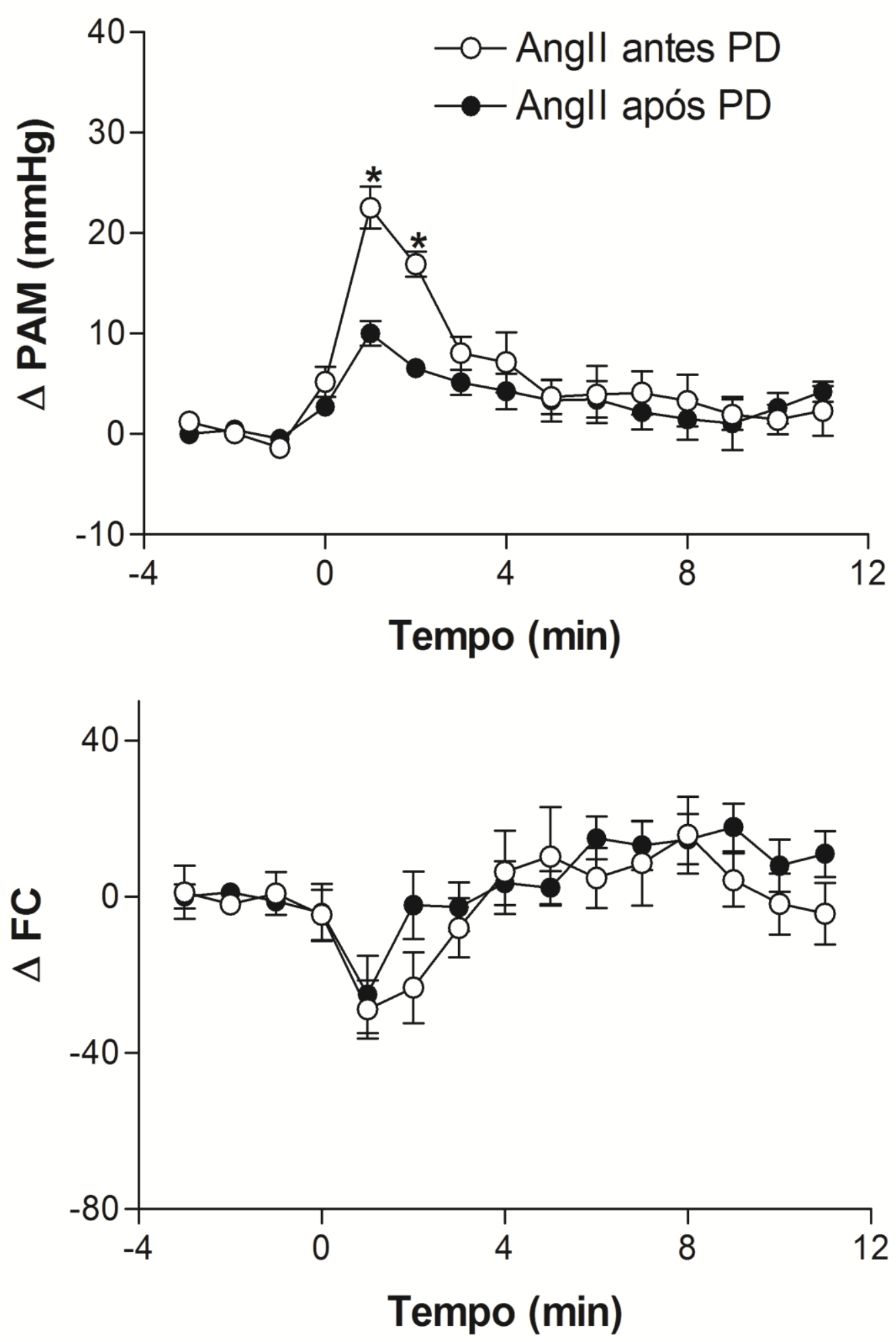

Figura 16. Variação da pressão arterial media $(\triangle \mathrm{PAM})$ e frequência cardíaca $(\triangle \mathrm{FC})$ ao longo do tempo após microinjeção de ANGII $(0,4 \mathrm{nmol} / 100 \mathrm{~nL})$ no $\mathrm{PL}$ antes (círculos brancos) e após (círculos pretos) o pré-tratamento com PD123319 $(1 \mathrm{nmol} / 100 \mathrm{~nL})$. As microinjeções foram feitas no tempo (zero). Os pontos representam as médias e as barras o EPM, $n=6,{ }^{*} P<0,05$, two-way ANOVA, pósteste de Bonferroni. 
10) Efeito da microinjeção de antagonista do receptor $\alpha_{1-}$ adrenérgico no PL sobre as respostas cardiovasculares à microinjeção local de ANGII

A microinjeção central de WB4101 (10nmol/100nL), antagonista seletivo de $\alpha_{1}$ - adrenérgico, não causou alterações significativas nos valores basais da PAM (ANTES: $98.46 \pm 4.90 \mathrm{mmHg}$; APÓS: $97.07 \pm 4.51 \mathrm{mmHg} ; \mathrm{t}=1.07 ; \mathrm{P}>0,05$; test de Student pareado, $n=5$ ) e na frequência cardíaca (ANTES: $358.5 \pm 6.89$ bpm; APÓS: $356.2 \pm 6.83$ bpm; $t=0.66 ; P>0,05 ;$ test $t$ de Student pareado, $n=5)$ de ratos não anestesiados.

O pré-tratamento local com WB 4101 atenuou a resposta pressora e a resposta bardicardíaca induzida pela administração ANGll no PL (Tratamento = PAM: $F_{1,120}=6,83 ; P<0,05$ e $F C: F_{1,120}=10,26 ; P<0,05 ;$ Tempo $=P A M: F_{14,120}=9,15 ; P$

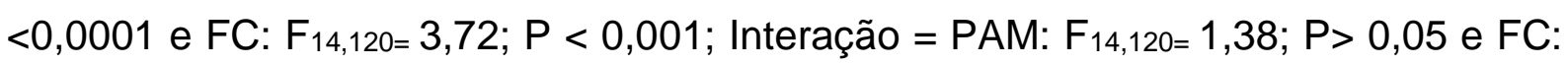
$F_{14,150=0,52 ;} P>0,05$; two-way ANOVA, pós teste de Bonferroni), (Figura 17).

A figura 18 mostra os diagramas representativos modificados do atlas de Paxinos e Watson (1997) indicando os sítios de microinjeção das diferentes doses de ANGII $(0,1,0,3,0,4,0,5$ e $1 \mathrm{nmoL})$, Candesartan $(0,03$ e $0,1 \mathrm{nmoL})$, CGP42112A (1 e 10nmoL), PD 123319 e LCA no PL. 

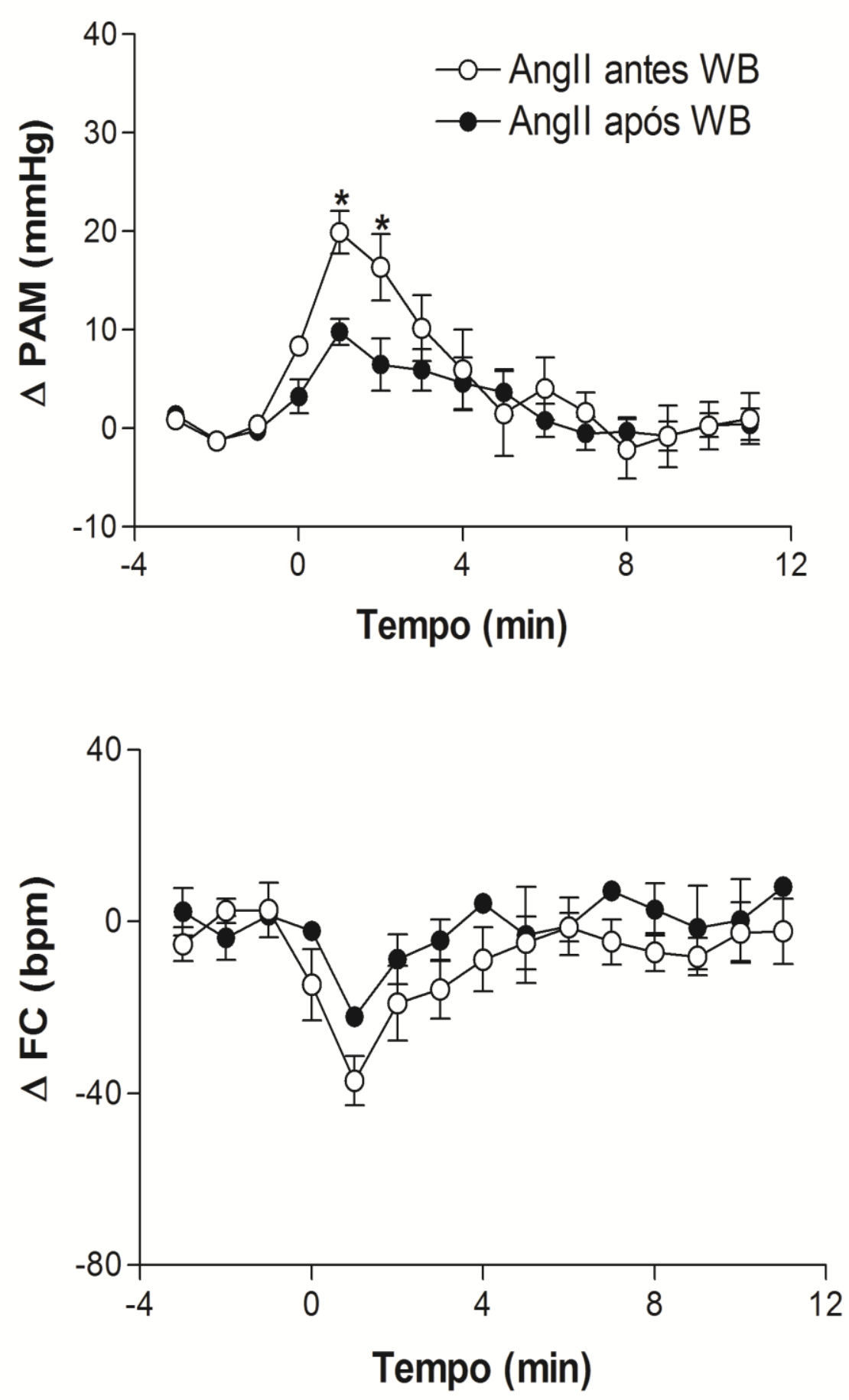

Figura 17. Variação da pressão arterial media $(\triangle \mathrm{PAM})$ e frequência cardíaca $(\triangle \mathrm{FC})$ ao longo do tempo após microinjeção de ANGII $(0,4 \mathrm{nmol} / 100 \mathrm{~nL})$ no $\mathrm{PL}$ antes (círculos brancos) e após (círculos pretos) o pré-tratamento com WB4101 $(10 \mathrm{nmol} / 100 \mathrm{~nL})$. As microinjeções foram feitas no tempo (zero). Os pontos representam as médias e as barras o EPM, $n=5$, * $P<0,05$, two-way ANOVA, pósteste de Bonferroni. 

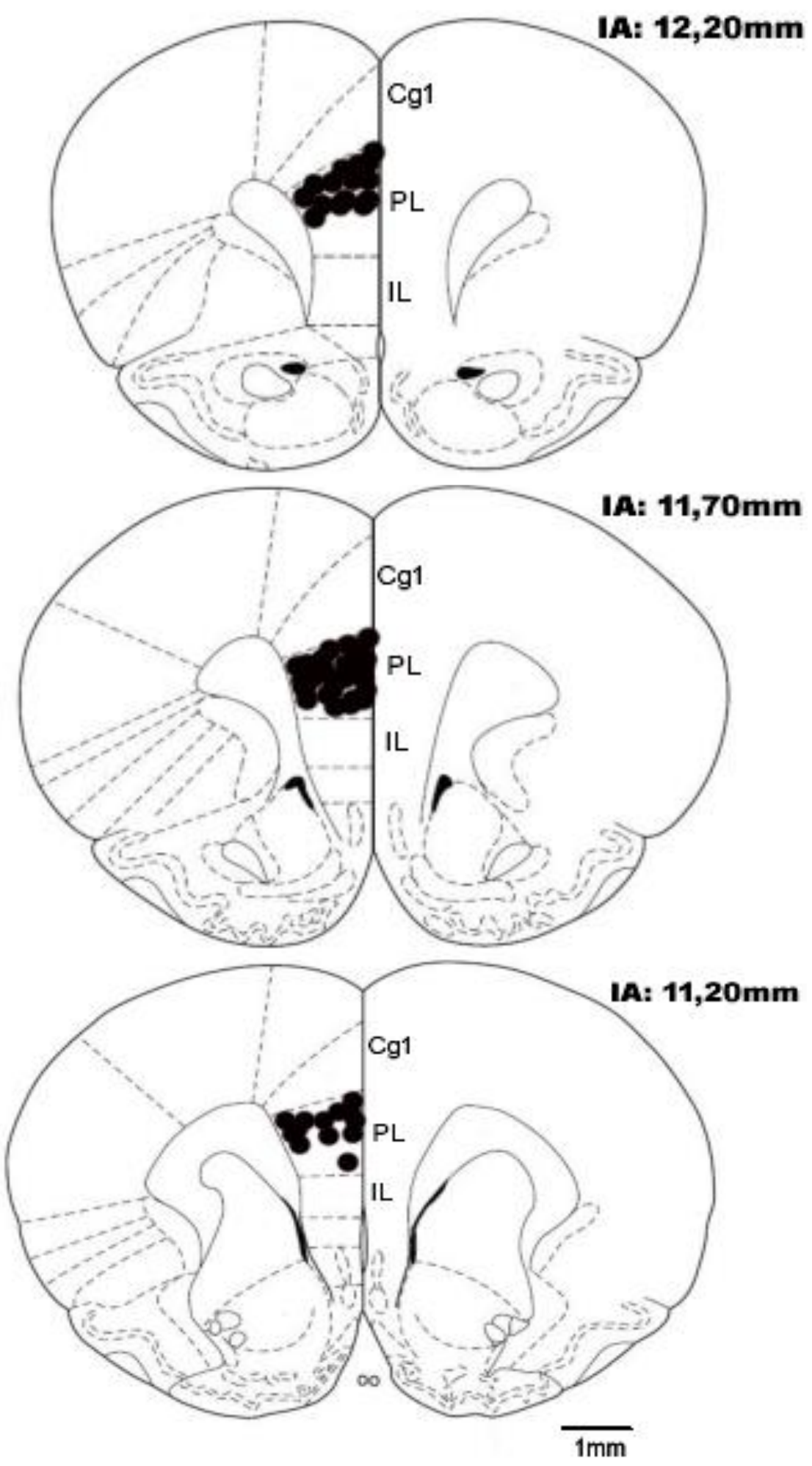

FIGURA 18 - Diagrama do cérebro de rato baseado no atlas Paxinos e Watson (1997) mostrando os sítios de microinjeção de drogas no PL indicando a dispersão dos sítios de microinjeção dos animais com ANGll (0,1, 0,3, 0,4, 0,5 e 1 nmoL), Candesartan (0,03 e 0,1 nmoL), CGP42112A (1 e 10nmoL), PD 123319 e LCA no PL. 
DISCUSSÃO 
No presente estudo demonstramos que a microinjeção de ANGll no PL causa respostas pressora e bradicárdica de forma dose-dependente. A microinjeção de LCA (veículo) no PL não causou alteração nas respostas cardiovasculares significantes. Este resultado exclui a possibilidade das respostas cardiovasculares observadas após microinjeção de ANGll no PL sejam decorrentes de estimulação mecânica da área.

A estimulação elétrica no CPFM gera resposta pressora (TAVARES, 2004), assim como estimulação química no PL com glutamato evoca respostas pressoras e taquicardíacas mediadas por ativação simpática. (RESSTEL; CORRÊA, 2005).

Estudos relatam que as alterações cardiovasculares após a injeção de ANGII em áreas encefálicas são mediadas via sistema autônomo simpático e/ou ativação humoral (AVERILL et al., 1994; HAACK; MÖHRING, 1978; QADRI et al., 1993). É descrito na literatura conexões entre o CPFM, em particular o PL, com regiões bulbares envolvidas na regulação do sistema nervoso simpático (VERBERNE; OWENS, 1998). Além disso, a administração de ANGll no RVLM causa resposta pressora e simpato-excitatória (AVERILL et al., 1994). Para investigar se as respostas pressora e bradicardíaca causadas pela microinjeção de ANGII no PL são mediadas pelo sistema simpático, os animais foram pré-tratados intravenosamente com um bloqueador ganglionar, pentolínio. O sistema nervoso simpático é o principal responsável pela manutenção do tônus vascular (GUYENET et al., 1990). A administração de pentolínio reduziu os valores basais de PAM sem alterar os valores de FC, confirmando o bloqueio simpático. O pré-tratamento com pentolínio não alterou a resposta pressora evocada pela administração de ANGII no PL, porém bloqueou o efeito bradicardíaco, sugerindo que o sistema autônomo simpático não esteja envolvido com a resposta pressora causada pela microinjeção 
de ANGII, e sugere que o efeito bradicardíaco observado seja decorrente de uma resposta baroreflexa vagal.

Os efeitos cardiovasculares do SRA podem ser mediados tanto pelo sistema nervoso simpático como pela liberação de vasopressina, e como o tratamento com pentolíneo não foi efetivo em alterar a resposta pressora causada pela microinjeção de ANGIl no PL, investigou-se a participação de fatores humorais nesta resposta.

A vasopressina ou hormônio antidiurético é um peptídeo sintetizado principalmente por células neurossecretórias dos neurônios magnocelulares no NPV e no NSO, transportada axonalmente na neuro-hipófise até sua liberação na circulação sistêmica (SWAAB; POOL; NIJVELDT, 1975) para agir sobre receptores vasopressinérgicos-V1 no músculo liso vascular (PHILLIPS et al., 1990) acoplados ao modelo de proteína $\mathrm{G}$ que estimula a enzima fosfolipase $\mathrm{C}$ formando segundos mensageiros, trifosfato de inositol (IP3) e diacilglicerol (BRILEY et al., 1994). Estes mensageiros por sua vez são capazes de elevar as concentrações intracelulares de cálcio livre, estimulando à contração da musculatura lisa vascular. Deste modo, a vasopressina sistêmica pode atuar em receptores V1 vasopressinérgicos, causando contração da musculatura lisa vascular (STEEDMAN, 1966) gerando aumento da pressão arterial. O principal estímulo para liberação de vasopressina é a diminuição da pressão arterial ou do volume sanguíneo e aumento da osmolalidade plasmática (CUNNINGHAM; PENNY; MURPHY, 2004).

Foi observada liberação de vasopressina em respostas pressoras de L-PRO no NSO (LOPES-AZEVEDO; BUSNARDO; CORREA, 2013); e L-glutamato (BUSNARDO et al., 2007); de noradrenalina i.c.v (CORREA et al., 1985), intraseptal (SCOPINHO et al., 2006); na substância cinzenta periaquedutal (PELOSI; CORREA, 2005) e no córtex (FERNANDES et al., 2003); bem como as respostas 
cardiovasculares causadas pela microinjeção i.c.v (SEVERS; DANIELS-SEVERS, 1973) ou intra-NOS (QADRI et al., 1993) de ANGII.

Para avaliar se a liberação periférica de vasopressina seria a via de efetivação da resposta à ANGII, os animais foram pré-tratados via intravenosa com um bloqueador de receptores vasopressinérgico do tipo $\mathrm{V} 1$, o dTyr(CH2)5(Me)AVP. A dose de dTyr(CH2)5(Me)AVP utilizada para inibir o constituinte vasopressinérgico das respostas pressoras a injeções centrais de neurotransmissores em ratos não anestesiados, foi utilizada a partir de trabalhos anteriores (BUSNARDO et al., 2007; SCOPINHO et al., 2006; TAVARES; DE AGUIAR CORREA, 2003; FERNANDES et al., 2003). O pré-tratamento com dTyr( $\mathrm{CH} 2) 5(\mathrm{Me}) \mathrm{AVP}$ bloqueou tanto a resposta pressora quanto a resposta bradicardíaca, sugerindo que o mecanismo efetuador desta resposta seja mediado por liberação sistêmica de vasopressina.

Uma vez caracterizado o mecanismo periférico efetuador da resposta à microinjeção de ANGll no PL, procuramos identificar o subtipo de receptor angiotensinérgico central envolvido nesta resposta.

Vários trabalhos na literatura sugerem a participação dos receptores $A T_{1}$ centrais na modulação de respostas cardiovasculares (D'AMICO et al., 1997; DU et al., 2013; TAGAWA; DAMPNEY, 1999; TAN et al., 2007). Os receptores AT1 presentes na porção medial do NTS modulam o baroreflexo cardíaco (TAN et al., 2007), enquanto o bloqueio desses receptores no RVLM reduz a PA em ratos com hipertensão induzida pelo estresse, sem alterar a PA de ratos normotensos (DU et al., 2013).

O losartan, antagonista clássico de receptores $A T_{1}$, é amplamente utilizado na clínica e em estudos experimentais, porém estudos de ligação revelam que o candesartan possui uma maior afinidade para o receptor $\mathrm{AT}_{1}$ quando comparada 
com outros antagonistas de receptores $A T_{1}$, como o losartan, por exemplo (BHUIYAN et al., 2009; BOSNYAK et al., 2011). Dessa forma, para investigar se os receptores $A T_{1}$ estariam envolvidos na mediação das respostas cardiovasculares evocada pela microinjeção de ANGll no PL os animais foram pré-tratados com candesartan, antagonista seletivo de receptores $A T_{1}$. O tratamento local com candesartan aboliu as respostas pressora e bradicardíaca induzida pela administração de ANGII no PL de maneira dose-dependente, sugerindo o envolvimento de receptores $A T_{1}$ nessa resposta. Corroborando com o presente estudo, o receptor AT1 participa das respostas cardiovasculares da ANGII em outras áreas encefálicas, como a PAG e o PVN (D'AMICO et al., 1997; GABOR; LEENEN, 2012).

Apesar do bloqueio dos receptores AT1 com candersatan reduzir as respostas cardiovasculares induzida pela ANGII administrada no PL, a investigação da participação dos receptores AT2 se faz necessária, visto que esses receptores estão presentes nessa estrutura (TSUTSUMI; SAAVEDRA, 1991; WRIGHT; HARDING, 1994) e desempenham um papel importante no controle cardiovascular principalmente contrabalanceando os efeitos da ativação dos receptores $\mathrm{AT}_{1}$ envolvidos com hipotensão, vasodilatação e vasoproteção (ARIMA et al., 1997; DIMITROPOULOU et al., 2001; DU et al., 2013; LEVY et al., 1996; MUNZENMAIER; GREENE, 1996).

Inicialmente, a ferramenta farmacológica utilizada para avaliar a participação dos receptores AT2 foi o CGP42112A. O pré-tratamento local com CGP42112A atenuou o aumento de PA e redução de FC decorrentes da microinjeção de ANGII no PL de maneira dose-dependente, demonstrando uma possível participação desses receptores nessa resposta cardiovascular. Os dados da literatura são 
controversos em relação ao papel farmacológico do CGP42112A, estudos demonstram sua atuação como antagonista de receptores AT2 (WRIGHT; HARDING, 1994), agonista parcial (BAUTISTA et al., 2001) e agonista pleno. Porém em um estudo no núcleo da oliva inferior, uma área predominantemente de receptores $A T_{2}$, sua caracterização como antagonista de receptores $A T_{2}$ é claramente observada. (AMBUHL et al., 1992; BUISSON et al., 1992). Devido a essas controvérsias em relação às propriedades farmacodinânicas do CGP42112A, a utilização de uma ferramenta farmacológica mais apropriada, como o PD123177,(DU et al., 2013; MATROUGUI et al., 1999; MCCARTHY et al., 2014; TIMMERMANS et al., 1991) antagonista seletivo de receptores AT2, se fez necessário para esclarecer o papel do receptor AT2 nessas respostas. O prétratamento do PL com PD123319 atenuou a resposta pressora e bradicardíaca desencadeada pela administração de ANGII local, demonstrando que esses receptores também estão envolvidos na resposta cardiovascular evocada por ANGII no PL.

Esses dados sugerem que ambos receptores $A T_{1}$ e $A T_{2}$ angiotensinérgicos estão envolvidos na mediação das respostas cardiovasculares à microinjeção de ANGII no PL.

Crestani e colaboradores (2008) observaram que as respostas cardiovasculares evocadas pela administração de noradrenalina no núcleo leito da estria terminal (NLET) eram mediadas por um mecanismo sinérgico entre os receptores $\alpha_{1}$ e $\alpha_{2}$ adrenérgicos; o bloqueio seletivo dos receptores $\alpha_{1}$ ou $\alpha_{2}$ adrenérgicos separadamente bloqueava parcialmente a resposta desencadeada pela noradrenalina nesse núcleo, porém, o bloqueio pleno era observado quando era administrada a combinação de WB4101 (antagonista de receptores $\alpha_{1}$-adrenérgicos) 
e RX821002 (antagonista de receptores $\alpha_{2}$-adrenérgicos), (CRESTANI et al., 2008). No entanto, no presente estudo foi observado que as respostas frente à microinjeção de ANGIl do PL eram bloqueadas com o pré-tratamento local com antagonista dos receptores $A T_{1}$ ou $A T_{2}$, em suas doses mais altas. Esse resultado sugere que possa haver vias distintas para a efetuação da resposta induzida pela ANGIl no PL, e descartam a possibilidade de uma ação complementar entre os dois receptores, ao contrário do observado por CRESTANI et al (2008) em relação à atuação dos receptores $\alpha_{1-/} \alpha_{2}$-adrenérgicos do NLET.

Alguns estudos demonstram que vias noradrenérgicas estão envolvidas com as respostas desencadeadas pela estimulação do RAS central. Campese e colaboradores (2005) demonstraram que a administração de ANGll i.c.v. estimula a liberação de noradrenalina no núcleo hipotalâmico posterior (CAMPESE; SHAOHUA; HUIQUIN, 2005). Corroborando com esse dado, Jones (1984) observou que a administração de fentolamina, antagonista não-seletivo de receptores $\alpha$ adrenérgicos na área pré-óptica anterior, abolia as respostas cardiovasculares e de consumo de água produzidas pela administração de angiotensina i.c.v. (JONES, 1984). Além disso, os receptores $A T_{1}$ parecem estar localizados nos neurônios présinápticos noradrenérgicos modulando a liberação de noradrenalina (TSUDA, 2012).

Estudo prévio do nosso laboratório demonstrou que a administração de noradrenalina no córtex pré-frontal medial, através da atuação em receptores $\boldsymbol{\alpha}_{1}$ adrenérgicos, causava respostas pressora e bradicárdiaca, medeiada pela liberação sistêmica de vasopressina (FERNANDES et al., 2003); resposta similar àquela observada após a microinjeção de ANGII no PL.

Nesse sentido, para estudar se as respostas cardiovasculares desencadeadas pela ANGII no PL dependiam da neurotransmissão noradrenérgica, 
foi utilizado o WB4101, antagonista de receptores $\alpha_{1}$-adrenérgico, mesmo receptor que estava envolvido com a resposta pressora e bradicardíaca evocada pela noradrenalina nessa estrutura (FERNANDES et al., 2003). O pré-tratamento do PL com WB4101 atenuou a resposta pressora sem alterar a resposta bradicardíaca evocada pela administração local ANGIl, sugerindo a participação da neurotransmissão noradrenérgica no desencadeamento da resposta cardiovascular evocada pela ANGII no PL. Porém mais estudos serão necessários para avaliar como ambos sistemas interagem.

Em conclusão, os presentes resultados sugerem que as respostas pressoras e bradicardíacas desencadeadas pela microinjeção de ANGIl no PL são mediadas pela liberação sistêmica de vasopressina; que os receptores angiotensinérgicos centrais $\mathrm{AT}_{1}$ e $\mathrm{AT}_{2}$ estão envolvidos nesta resposta, e que essa resposta é parcialmente dependente de receptores $\alpha 1$-adrenérgicos presentes no PL. 
REFERÊNCIAS BIBLIOGRÁFICAS 
AMBUHL, P. et al. Effects of angiotensin II and its selective antagonists on inferior olivary neurones. Regul Pept, v. 41, n. 1, p. 19-26 1992.

ANDREATTA, S. H. et al. The ventrolateral medulla. A new site of action of the renin-angiotensin system. Hypertension, v. 11, n. 2 Pt 2, p. I163-166 1988.

ARIMA, S. et al. Possible role of P-450 metabolite of arachidonic acid in vasodilator mechanism of angiotensin II type 2 receptor in the isolated microperfused rabbit afferent arteriole. J Clin Invest, v. 100, n. 11, p. 2816-2823 1997.

AVERILL, D. B. et al. Losartan, nonpeptide angiotensin II-type 1 (AT1) receptor antagonist, attenuates pressor and sympathoexcitatory responses evoked by angiotensin II and L-glutamate in rostral ventrolateral medulla. Brain Res, v. 665, n. 2, p. 245-252 1994.

BATIN, P. et al. Cardiac haemodynamic effects of the non-peptide, angiotensin IIreceptor antagonist, DuP 753, in conscious Long Evans and Brattleboro rats. $\mathbf{B r} \mathbf{J}$ Pharmacol, v. 103, n. 2, p. 1585-1591 1991.

BENICKY, J. et al. Angiotensin II AT1 receptor blockade ameliorates brain inflammation. Neuropsychopharmacology, v. 36, n. 4, p. 857-870 2011.

BERTRAM, D.; COOTE, J. H. Inhibitory effects of angiotensin II on barosensitive rostral ventrolateral medulla neurons of the rat. Clin Exp Pharmacol Physiol, v. 28, n. 12, p. 1112-1114 2001.

BHUIYAN, M. A. et al. Binding sites of valsartan, candesartan and losartan with angiotensin II receptor 1 subtype by molecular modeling. Life Sci, v. 85, n. 3-4, p. 136-140 2009.

BICKERTON, R. K.; BUCKLEY, J. Evidence for a central mechanism in angiotensininduced hypertension. Proc Soc Exp Biol Med, v. 106, p. 8341961.

BOSNYAK, S. et al. Relative affinity of angiotensin peptides and novel ligands at AT1 and AT2 receptors. Clin Sci (Lond), v. 121, n. 7, p. 297-303 2011.

BREIGEIRON, M. K. et al. Effects of angiotensin II microinjected into medial amygdala on male sexual behavior in rats. Horm Behav, v. 41, n. 3, p. 267-274 2002.

BRILEY, E. M. et al. The cloned vasopressin V1a receptor stimulates phospholipase A2, phospholipase $C$, and phospholipase $D$ through activation of receptor-operated calcium channels. Neuropeptides, v. 27, n. 1, p. 63-74 1994. 
BUISSON, B. et al. The angiotensin AT2 receptor modulates T-type calcium current in non-differentiated NG108-15 cells. FEBS Lett, v. 309, n. 2, p. 161-164 1992.

BUMPUS, F. M. et al. Nomenclature for angiotensin receptors. A report of the Nomenclature Committee of the Council for High Blood Pressure Research. Hypertension, v. 17, n. 5, p. 720-721 1991.

BURNS, S. M.; WYSS, J. M. The involvement of the anterior cingulate cortex in blood pressure control. Brain Res, v. 340, n. 1, p. 71-77 1985.

BUSNARDO, C. et al. Cardiovascular effects of L-glutamate microinjection in the supraoptic nucleus of unanaesthetized rats. Neuropharmacology, v. 52, n. 6, p. 1378-1384 2007.

CAMPESE, V. M.; SHAOHUA, Y.; HUIQUIN, Z. Oxidative stress mediates angiotensin II-dependent stimulation of sympathetic nerve activity. Hypertension, $v$. 46, n. 3, p. 533-539 2005.

CHAI, S. Y.; MCKINLEY, M. J.; MENDELSOHN, F. A. Distribution of angiotensin converting enzyme in sheep hypothalamus and medulla oblongata visualized by in vitro autoradiography. Clin Exp Hypertens A, v. 9, n. 2-3, p. 449-460 1987.

CHALMERS, J.; PILOWSKY, P. Brainstem and bulbospinal neurotransmitter systems in the control of blood pressure. J Hypertens, v. 9, n. 8, p. 675-694 1991.

CHIARAVIGLIO, E. Effect of renin-angiotensin system on sodium intake. J Physiol, v. 255, n. 1, p. 57-66 1976.

CHIU, A. T. et al. Identification of angiotensin II receptor subtypes. Biochem Biophys Res Commun, v. 165, n. 1, p. 196-203 1989.

COLOMBARI, D.; CORREA, F. Estudo de mecanismos angiotensinérgicos do órgão subfornical e serotonérgicos do núcleo parabraquial lateral envolvidos em controle cardiovascular e hidroeletrolítico no rato. 1995. Farmacologia, Universidade de São Paulo, Ribeirão Preto.

CORREA, F. M. et al. Mechanism of the CNS-mediated pressor response to intracerebroventricular injection of noradrenaline in unanaesthetized rats. Neuropharmacology, v. 24, n. 9, p. 831-837 1985.

CRESTANI, C. C. et al. Both alpha1 and alpha2-adrenoceptors mediate the cardiovascular responses to noradrenaline microinjected into the bed nucleus of the stria terminal of rats. Br J Pharmacol, v. 153, n. 3, p. 583-590 2008. 
CUNNINGHAM, J. T.; PENNY, M. L.; MURPHY, D. Cardiovascular regulation of supraoptic neurons in the rat: synaptic inputs and cellular signals. Prog Biophys Mol Biol, v. 84, n. 2-3, p. 183-196 2004.

D'AMICO, M. et al. AT1 receptors mediate pressor responses induced by angiotensin II in the periaqueductal gray area of rats. Life Sci, v. 61, n. 1, p. PL17-20 1997.

DAMPNEY, R. A. Functional organization of central pathways regulating the cardiovascular system. Physiol Rev, v. 74, n. 2, p. 323-364 1994.

DAMPNEY, R. A. et al. Afferent connections and spinal projections of the pressor region in the rostral ventrolateral medulla of the cat. J Auton Nerv Syst, v. 20, n. 1, p. 73-86 1987.

DESCHEPPER, C. F.; BOUHNIK, J.; GANONG, W. F. Colocalization of angiotensinogen and glial fibrillary acidic protein in astrocytes in rat brain. Brain Res, v. 374, n. 1, p. 195-198 1986.

DIMITROPOULOU, C. et al. Angiotensin II relaxes microvessels via the AT(2) receptor and $\mathrm{Ca} 2+-$ activated $\mathrm{K}+(\mathrm{BKCa})$ channels. Hypertension, v. 37, n. 2, p. 3013072001.

DU, D. et al. The effects of angiotensin II and angiotensin-(1-7) in the rostral ventrolateral medulla of rats on stress-induced hypertension. PLoS One, v. 8, n. 8, p. e70976 2013.

FERGUSON, A. V.; WASHBURN, D. L.; LATCHFORD, K. J. Hormonal and neurotransmitter roles for angiotensin in the regulation of central autonomic function. Exp Biol Med (Maywood), v. 226, n. 2, p. 85-96 2001.

FERNANDES, K. B. et al. Mechanisms involved in the pressor response to noradrenaline injection into the cingulate cortex of unanesthetized rats. Neuropharmacology, v. 44, n. 6, p. 757-763 2003.

FERREIRA-JUNIOR, N. C. et al. Medial prefrontal cortex endocannabinoid system modulates baroreflex activity through $\mathrm{CB}(1)$ receptors. Am J Physiol Regul Integr Comp Physiol, v. 302, n. 7, p. R876-885 2012.

FISK, G. D.; WYSS, J. M. Pressor and depressor sites are intermingled in the cingulate cortex of the rat. Brain Res, v. 754, n. 1-2, p. 204-212 1997.

FISK, G. D.; WYSS, J. M. Descending projections of infralimbic cortex that mediate stimulation-evoked changes in arterial pressure. Brain Res, v. 859, n. 1, p. 83-95 2000. 
FORTALEZA, E. A.; SCOPINHO, A. A.; CORRÊA, F. M. Cardiovascular responses to microinjection of noradrenaline into the medial amygdaloid nucleus of conscious rats result from $\alpha_{2}$-receptor activation and vasopressin release. Eur $\mathbf{J}$ Neurosci, v. 33, n. 9, p. 1677-1684 2011.

GABOR, A.; LEENEN, F. H. Cardiovascular effects of angiotensin II and glutamate in the PVN of Dahl salt-sensitive rats. Brain Res, v. 1447, p. 28-37 2012.

GOLDSTEIN, D. S. Central catecolamines and the control of sympathetic tone. . In: KUNOS, G. e CIRELLO, J. (Ed.). Boston: Cardiovascular Regulation, v.2, 1991. (Central Neural Mechanisms).

GOODCHILD, A. K.; DAMPNEY, R. A.; BANDLER, R. A method for evoking physiological responses by stimulation of cell bodies, but not axons of passage, within localized regions of the central nervous system. J Neurosci Methods, v. 6, n. 4, p. 351-363 1982.

GUYENET, P. G. The sympathetic control of blood pressure. Nat Rev Neurosci, v. 7, n. 5, p. 335-346 2006.

GUYENET, P. G.; DARNALL, R. A.; RILEY, T. A. Rostral ventrolateral medulla and sympathorespiratory integration in rats. Am J Physiol, v. 259, n. 5 Pt 2, p. R106310741990.

HAACK, D.; MÖHRING, J. Vasopressin-mediated blood pressure response to intraventricular injection of angiotensin II in the rat. Pflugers Arch, v. 373, n. 2, p. 167-173 1978.

HALL, J. E. Control of blood pressure by the renin-angiotensin-aldosterone system. Clin Cardiol, v. 14, n. 8 Suppl 4, p. IV6-21; discussion IV51-25 1991.

HÄUSER, W.; JÖHREN, O.; SAAVEDRA, J. M. Characterization and distribution of angiotensin II receptor subtypes in the mouse brain. Eur $\mathbf{J}$ Pharmacol, v. 348, n. 1, p. 101-114 1998.

HEALY, D. P.; PRINTZ, M. P. Distribution of immunoreactive angiotensin II, angiotensin I, angiotensinogen and renin in the central nervous system of intact and nephrectomized rats. Hypertension, v. 6, n. 2 Pt 2, p. 1130-136 1984.

HERMANN, K. et al. Presence of renin in primary neuronal and glial cells from rat brain. Brain Res, v. 437, n. 2, p. 205-213 1987.

HILTON, S. M. Hypothalamic regulation of the cardiovascular system. Br Med Bull, v. 22, n. 3, p. 243-248 1966. 
JONES, D. L. Injections of phentolamine into the anterior hypothalamus-preoptic area of rats blocks both pressor and drinking responses produced by central administration of angiotensin II. Brain Res Bull, v. 13, n. 1, p. 127-133 1984.

KRUSZYNSKI, M. et al. [1-beta-Mercapto-beta,beta-cyclopentamethylenepropionic acid),2-(O-methyl)tyrosine ]argine-vasopressin and [1-beta-mercapto-beta,betacyclopentamethylenepropionic acid)]argine-vasopressine, two highly potent antagonists of the vasopressor response to arginine-vasopressin. J Med Chem, v. 23, n. 4, p. 364-368 1980.

LENKEI, Z. et al. Expression of angiotensin type-1 (AT1) and type-2 (AT2) receptor mRNAs in the adult rat brain: a functional neuroanatomical review. Front Neuroendocrinol, v. 18, n. 4, p. 383-439 1997.

LEVY, B. I. et al. Chronic blockade of ATP-subtype receptors prevents the effect of angiotensin II on the rat vascular structure. Journal of Clinical Investigation, v. 98, n. 2, p. 418-425 1996.

LIND, R. W.; SWANSON, L. W.; GANTEN, D. Organization of angiotensin II immunoreactive cells and fibers in the rat central nervous system. An immunohistochemical study. Neuroendocrinology, v. 40, n. 1, p. 2-24 1985.

LOEWY, A. D. Forebrain nuclei involved in autonomic control. Prog Brain Res, v. 87, p. 253-268 1991.

LOEWY, A. D.; MCKELLAR, S. The neuroanatomical basis of central cardiovascular control. Fed Proc, v. 39, n. 8, p. 2495-2503 1980.

LOPES-AZEVEDO, S.; BUSNARDO, C.; CORREA, F. M. Mechanism of the cardiovascular responses caused by L-proline microinjected into the supraoptic nucleus of the hypothalamus in unanesthetized rats. Amino Acids, v. 45, n. 4, p. 797-810 2013.

LÓPEZ, L. H. et al. Anxiolytic-like effect of losartan injected into amygdala of the acutely stressed rats. Pharmacol Rep, v. 64, n. 1, p. 54-63 2012.

MATHAI, M.; EVERED, M. D.; MCKINLEY, M. J. Intracerebroventricular losartan inhibits postprandial drinking in sheep. Am J Physiol, v. 272, n. 4 Pt 2, p. R105510591997.

MATROUGUI, $K$. et al. Activation of AT(2) receptors by endogenous angiotensin II is involved in flow-induced dilation in rat resistance arteries. Hypertension, v. 34, n. 4 Pt 1, p. 659-665 1999. 
MATSUMURA, K. et al. Central effects of leptin on cardiovascular and neurohormonal responses in conscious rabbits. Am J Physiol Regul Integr Comp Physiol, v. 278, n. 5, p. R1314-1320 2000.

MCCARTHY, C. A. et al. Direct angiotensin AT2 receptor stimulation using a novel AT2 receptor agonist, compound 21, evokes neuroprotection in conscious hypertensive rats. PLoS One, v. 9, n. 4, p. e95762 2014.

MENDELSOHN, F. A. et al. Characteristics and regulation of angiotensin II receptors in pituitary, circumventricular organs and kidney. Clin Exp Hypertens A, v. 5, n. 7-8, p. 1081-1097 1983.

MENDELSOHN, F. A. et al. Autoradiographic localization of angiotensin II receptors in rat brain. Proc Natl Acad Sci U S A, v. 81, n. 5, p. 1575-1579 1984.

MIURA, M.; REIS, D. J. Termination and secondary projections of carotid sinus nerve in the cat brain stem. Am J Physiol, v. 217, n. 1, p. 142-153 1969.

MORIGUCHI, S. et al. Central administration of a nitric oxide synthase inhibitor causes pressor responses via the sympathetic nervous system and the reninangiotensin system in Wistar rats. Neurosci Lett, v. 245, n. 2, p. 109-112 1998.

MUNZENMAIER, D. H.; GREENE, A. S. Opposing actions of angiotensin II on microvascular growth and arterial blood pressure. Hypertension, v. 27, n. 3 Pt 2, p. 760-765 1996.

NEAFSEY, E. J. Prefrontal cortical control of the autonomic nervous system: anatomical and physiological observations. Prog Brain Res, v. 85, p. 147-165; discussion 165-1461990.

NUNES, F. C.; BRAGA, V. A. Chronic angiotensin II infusion modulates angiotensin II type I receptor expression in the subfornical organ and the rostral ventrolateral medulla in hypertensive rats. J Renin Angiotensin Aldosterone Syst, v. 12, n. 4, p. 440-445 2011.

OSBORN, J. W. et al. The role of the subfornical organ in angiotensin II-salt hypertension in the rat. Exp Physiol, v. 97, n. 1, p. 80-88 2012.

OWENS, N. C.; SARTOR, D. M.; VERBERNE, A. J. Medial prefrontal cortex depressor response: role of the solitary tract nucleus in the rat. Neuroscience, v. 89, n. 4, p. 1331-1346 1999. 
OWENS, N. C.; VERBERNE, A. J. Medial prefrontal depressor response: involvement of the rostral and caudal ventrolateral medulla in the rat. $\mathbf{J}$ Auton Nerv Syst, v. 78, n. 2-3, p. 86-93 2000.

PAGE, I. $H$. et al. SUGGESTED CHANGE IN DESIGNATION OF "RENINACTIVATOR" (HYPERTENSINOGEN) TO RENIN-SUBSTRATE (agr GLOBULIN). Science, v. 98, n. 2537, p. 153-154 1943.

PAXINOS, G.; WATSON, C. The rat brain stereotaxic coordinates. 3. Sydney: Academic Press, 1997.

PEACH, M. J. Renin-angiotensin system: biochemistry and mechanisms of action. Physiol Rev, v. 57, n. 2, p. 313-370 1977.

PELOSI, G. G.; CORREA, F. M. Cardiovascular effects of noradrenaline microinjected into the dorsal periaqueductal gray area of unanaesthetized rats. Eur $\mathbf{J}$ Neurosci, v. 22, n. 12, p. 3188-31942005.

PHILLIPS, P. A. et al. Localization of vasopressin binding sites in rat tissues using specific V1 and V2 selective ligands. Endocrinology, v. 126, n. 3, p. 1478-1484 1990.

PRINTZ, M. et al. Minireview: the brain renin-angiotensin system. In: GARTEN, D.;PRINTZ, M., et al (Ed.). Berlin: Springer, v.04, 1982. p.3-52.

QADRI, F. et al. Angiotensin II-induced vasopressin release is mediated through alpha-1 adrenoceptors and angiotensin II AT1 receptors in the supraoptic nucleus. $\mathbf{J}$ Pharmacol Exp Ther, v. 267, n. 2, p. 567-574 1993.

QI, J. et al. Renin-Angiotensin System Modulates Neurotransmitters in the Paraventricular Nucleus and Contributes to Angiotensin II-Induced Hypertensive Response. Cardiovasc Toxicol, v. 13, n. 1, p. 48-54 2013.

RESSTEL, L. B.; CORREA, F. M. Injection of I-glutamate into medial prefrontal cortex induces cardiovascular responses through NMDA receptor - nitric oxide in rat. Neuropharmacology, v. 51, n. 1, p. 160-167 2006.

RESSTEL, L. B.; CORREAA, F. M. Pressor and tachycardic responses evoked by microinjections of L-glutamate into the medial prefrontal cortex of unanaesthetized rats. Eur J Neurosci, v. 21, n. 9, p. 2513-2520 2005.

RESSTEL, L. B.; FERNANDES, K. B.; CORREAA, F. M. Medial prefrontal cortex modulation of the baroreflex parasympathetic component in the rat. Brain Res, $v$. 1015, n. 1-2, p. 136-144 2004. 
SAAVEDRA, J. M. Brain and pituitary angiotensin. Endocr Rev, v. 13, n. 2, p. 3293801992.

SAAVEDRA, J. M. et al. Quantitative distribution of angiotensin II binding sites in rat brain by autoradiography. Peptides, v. 7, n. 4, p. 679-687 1986.

SASAKI, S.; DAMPNEY, R. A. Tonic cardiovascular effects of angiotensin II in the ventrolateral medulla. Hypertension, v. 15, n. 3, p. 274-283 1990.

SCOPINHO, A. A. et al. Pressor effects of noradrenaline injected into the lateral septal area of unanesthetized rats. Brain Res, v. 1122, n. 1, p. 126-134 2006.

SEVERS, W. B.; DANIELS-SEVERS, A. E. Effects of angiotensin on the central nervous system. Pharmacol Rev, v. 25, n. 3, p. 415-449 1973.

STADLER, T. et al. Angiotensin II evokes noradrenaline release from the paraventricular nucleus in conscious rats. Brain Res, v. 569, n. 1, p. 117-122 1992.

STEEDMAN, W. M. Micro-electrode studies on mammalian vascular muscle. J Physiol, v. 186, n. 2, p. 382-400 1966.

STORNETTA, R. L. et al. Astrocytes synthesize angiotensinogen in brain. Science, v. 242, n. 4884, p. 1444-1446 1988.

SWAAB, D. F.; POOL, C. W.; NIJVELDT, F. Immunofluorescence of vasopressin and oxytocin in the rat hypothalamo-neurohypophypopseal system. J Neural Transm, v. 36, n. 3-4, p. 195-215 1975.

TAGAWA, T.; DAMPNEY, R. A. AT(1) receptors mediate excitatory inputs to rostral ventrolateral medulla pressor neurons from hypothalamus. Hypertension, v. 34, n. 6, p. 1301-1307 1999.

TAN, P. S. et al. Baroreceptor reflex modulation by circulating angiotensin II is mediated by AT1 receptors in the nucleus tractus solitarius. Am $\mathbf{J}$ Physiol Regul Integr Comp Physiol, v. 293, n. 6, p. R2267-2278 2007.

TAVARES, R. F.; ANTUNES-RODRIGUES, J.; DE AGUIAR CORREAA, F. M. Pressor effects of electrical stimulation of medial prefrontal cortex in unanesthetized rats. $\mathbf{J}$ Neurosci Res, v. 77, n. 4, p. 613-620 2004.

TAVARES, R. F.; DE AGUIAR CORREA, F. M. Pressor effects of L-glutamate injected into the diagonal band of Broca of unanesthetized rats. Brain Res, v. 959, n. 2, p. 312-319 2003. 
TAYLOR, E. W.; JORDAN, D.; COOTE, J. H. Central control of the cardiovascular and respiratory systems and their interactions in vertebrates. Physiol Rev, v. 79, n. 3, p. 855-916 1999.

THOMAS, W. G.; SERNIA, C. Immunocytochemical localization of angiotensinogen in the rat brain. Neuroscience, v. 25, n. 1, p. 319-341 1988.

TIMMERMANS, P. B. et al. Angiotensin II receptor subtypes. Am J Hypertens, v. 5, n. 6 Pt 1, p. 406-410 1992.

TIMMERMANS, P. B. et al. Nonpeptide angiotensin II receptor antagonists. Trends Pharmacol Sci, v. 12, n. 2, p. 55-62 1991.

TSUDA, K. Renin-Angiotensin system and sympathetic neurotransmitter release in the central nervous system of hypertension. Int J Hypertens, v. 2012, p. 474870 2012.

TSUTSUMI, K.; SAAVEDRA, J. M. Characterization and development of angiotensin II receptor subtypes (AT1 and AT2) in rat brain. Am J Physiol, v. 261, n. 1 Pt 2, p. R209-216 1991.

VERBERNE, A. J. Cuneiform nucleus stimulation produces activation of medullary sympathoexcitatory neurons in rats. Am J Physiol, v. 268, n. 3 Pt 2, p. R752-758 1995.

VERBERNE, A. J. Medullary sympathoexcitatory neurons are inhibited by activation of the medial prefrontal cortex in the rat. Am J Physiol, v. 270, n. 4 Pt 2, p. R7137191996.

VERBERNE, A. J.; GUYENET, P. G. Midbrain central gray: influence on medullary sympathoexcitatory neurons and the baroreflex in rats. Am J Physiol, v. 263, n. $1 \mathrm{Pt}$ 2, p. R24-33 1992.

VERBERNE, A. J.; OWENS, N. C. Cortical modulation of the cardiovascular system. Prog Neurobiol, v. 54, n. 2, p. 149-168 1998.

WRIGHT, J. W.; HARDING, J. W. Brain angiotensin receptor subtypes in the control of physiological and behavioral responses. Neurosci Biobehav Rev, v. 18, n. 1, p. 21-53 1994. 